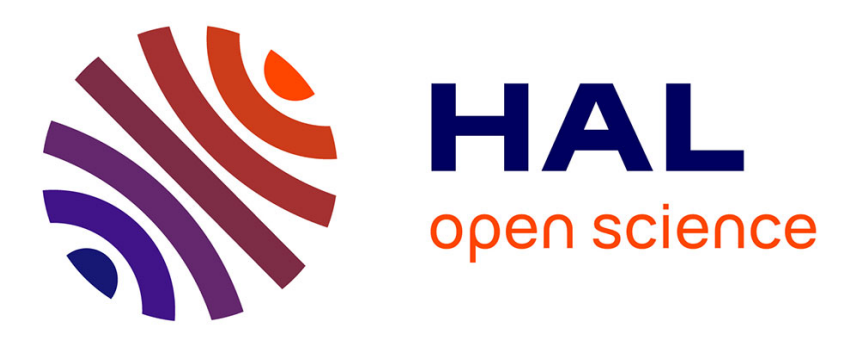

\title{
Monitoring volcanic thermal anomalies from space: Size matters
}

Samuel William Murphy, Carlos Roberto de Souza Flilho, Clive Oppenheimer

\section{To cite this version:}

Samuel William Murphy, Carlos Roberto de Souza Flilho, Clive Oppenheimer. Monitoring volcanic thermal anomalies from space: Size matters. Journal of Volcanology and Geothermal Research, 2011, 203 (1-2), pp.48-61. 10.1016/j.jvolgeores.2011.04.008 . insu-00587420

\section{HAL Id: insu-00587420 \\ https://hal-insu.archives-ouvertes.fr/insu-00587420}

Submitted on 9 May 2012

HAL is a multi-disciplinary open access archive for the deposit and dissemination of scientific research documents, whether they are published or not. The documents may come from teaching and research institutions in France or abroad, or from public or private research centers.
L'archive ouverte pluridisciplinaire HAL, est destinée au dépôt et à la diffusion de documents scientifiques de niveau recherche, publiés ou non, émanant des établissements d'enseignement et de recherche français ou étrangers, des laboratoires publics ou privés. 


\title{
Monitoring volcanic thermal anomalies from space: Size matters
}

- Samuel William Murphy ${ }^{\mathrm{a}}$

- Carlos Roberto de Souza Filho

- Clive Oppenheimer $\underline{\underline{b}, \underline{c}, \underline{d}}$

- ${ }^{a}$ Department of Geology and Natural Resources, Geosciences Institute, University of Campinas (UNICAMP), Campinas, Sao Paulo, CEP: 13983-970, Brazil

- $\quad{ }^{\mathrm{b}}$ Le Studium, Institute for Advanced Studies, Orléans and Tours, France

- $\quad{ }^{\mathrm{c}}$ L'Institut des Sciences de la Terre d'Orléans, l'Université d'Orléans, 1a rue de la Férollerie, 45071 Orléans, cedex 2, France

- ${ }^{\mathrm{d}}$ Department of Geography, University of Cambridge, Downing Place, CB2 3EN, Cambridge, United Kingdom

\begin{abstract}
Measuring temperatures on volcanoes from space provides important constraints on the transfer of mass and heat to the Earth's surface. Time series of multispectral infrared images, acquired by the Advanced Spaceborne Thermal Emission and Reflection Radiometer (ASTER) between 2000 and 2009, were inspected to investigate fluctuations in thermal anomalies at both Mount Erebus (Antarctica) and Láscar volcano (Chile). Several thermal metrics were explored: i) maximum pixel temperatures above background, ii) the spatial extent of low, moderate and high temperature anomalies, and iii) the spatial extent of shortwave infrared anomalies. The maximum pixel temperature metric correlated to eruptive events at Láscar volcano yet displayed significant scatter at Erebus. The spatial extent of both temperature and short-wave infrared anomalies correlates well with eruptive activity at both volcanoes.
\end{abstract}

Limited variation in the size of thermal anomalies was observed at Erebus throughout the time series due to the stability of a long-lived lava lake, with the exception of a seasonal expansion in low temperature anomalies associated with localized snow-melt at the peak. This finding has implications for the interpretation of low temperature anomalies at other volcanoes. At least two different types of precursory signals are identified at Láscar: i) a gradual increase and ii) a dip, in the size and intensity of thermal anomalies. These thermal precursors appear to be associated with different eruptive styles. The former precedes a relatively shallow, short lived eruption; the later a prolonged eruptive period. Such thermal precursors could therefore help to constrain not only the timing but also the style and duration of an imminent eruptive episode.

Keywords : volcano; monitoring; ASTER; Láscar; Erebus

\section{Introduction}

Volcanoes are hazardous, non-linear systems and so require regular monitoring if timely forecasts of eruptive behavior are to be given and if we are to improve our understanding of dynamic volcanic processes. Ideally volcanologists would have access to information from all of the world's subaerial volcanoes. This way a greater understanding of fundamental volcanic processes can contribute to the expert knowledge required to deal with specific volcanoes that 
may be endangering communities or property. Orbital remote sensing provides the necessary perspective to fulfill such an ideal and is often the only source of information available for many remote volcanoes.

The approach adopted in this study is to measure the temperature of active volcanoes from space using multispectral thermal infrared (TIR) images taken by the Advanced Spaceborne Thermal Emission and Reflection Radiometer (ASTER), currently the only multispectral TIR sensor in orbit with moderate $(<100 \mathrm{~m})$ spatial resolution imagery that is available to the civilian community. Previous authors have utilized the combined spatial and spectral resolution of this sensor to describe volcanic activity. Special consideration has been given to the reliability of terrestrial surface temperature estimates at these wavelengths (i.e. 8.125$11.65 \mu \mathrm{m})$. The metrics used to quantify such observations have included the maximum pixel temperature ( [Ramsey and Dehn, 2004], [Vaughan and Hook, 2006] and [Carter et al., 2008]), the average crater temperature (Vaughan and Hook, 2006) and the maximum pixel temperature above background ( [Ramsey and Dehn, 2004], [Pieri and Abrams, 2005], [Vaughan et al., 2008] and [Carter et al., 2008]). Although these thermal parameters were all shown to correlate with volcanic activity, they do not measure the actual size of the anomaly (Carter et al., 2008). This study aims toward developing methods for measuring both the size and intensity of volcanic thermal anomalies. We further support the investigation of TIRbased thermal anomalies by comparison to ASTER's short-wave infrared (SWIR) bands.

In order to explore an existing TIR-based parameter we first analyze temporal fluctuations in maximum pixel temperature above background. This parameter was selected because it is the most widely adopted in the previous literature, accounts for non-volcanic seasonal variations in temperature and has been shown to correlate particularly well with eruptive behavior. We then describe the change in the size and intensity of thermal anomalies (both TIR- and SWIRbased) through time at Mt. Erebus (Antarctica) and Láscar (Chile). These targets exhibit markedly different styles of volcanism and are situated thousands of kilometers apart from each other, thus providing a contrast in eruptive styles as well as demonstrating one of the advantages of the global perspective available from space.

\section{Study areas}

\subsection{Erebus volcano}

Erebus volcano $\left(77^{\circ} 32^{\prime} \mathrm{S}, 167^{\circ} 10^{\prime} \mathrm{E}, 3794 \mathrm{~m}\right)$ is an alkaline intraplate stratovolcano situated on Ross Island, Antarctica (Fig. 1) ( [Kyle et al., 1992] and [Oppenheimer et al., 2011]). It contains one of the few permanent, terrestrial lava lakes. The bulk composition of its phonolitic lava appears to have remained unchanged over the last $~ 36 \mathrm{ka}$ ( [Harpel et al., 2004], [Esser et al., 2004] and [Kelly et al., 2008]). The lake is thought to be sustained by magma convection via a conduit leading to a reservoir at depth. The first historical sighting of the volcano was reported in 1841 (Ross, 1847), with a lava lake having been observed in the active crater since modern observations began in 1972 (Giggenbach et al., 1973). 
A
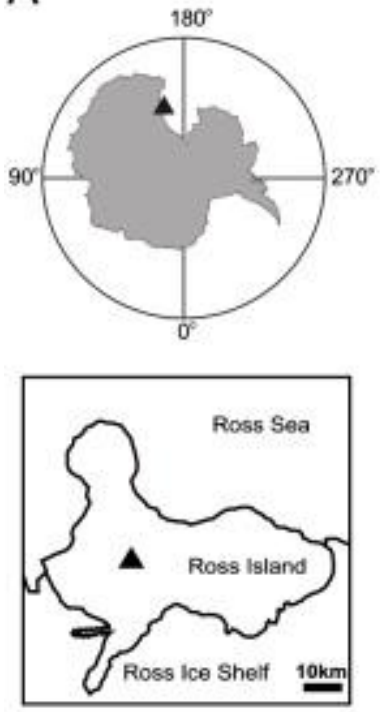

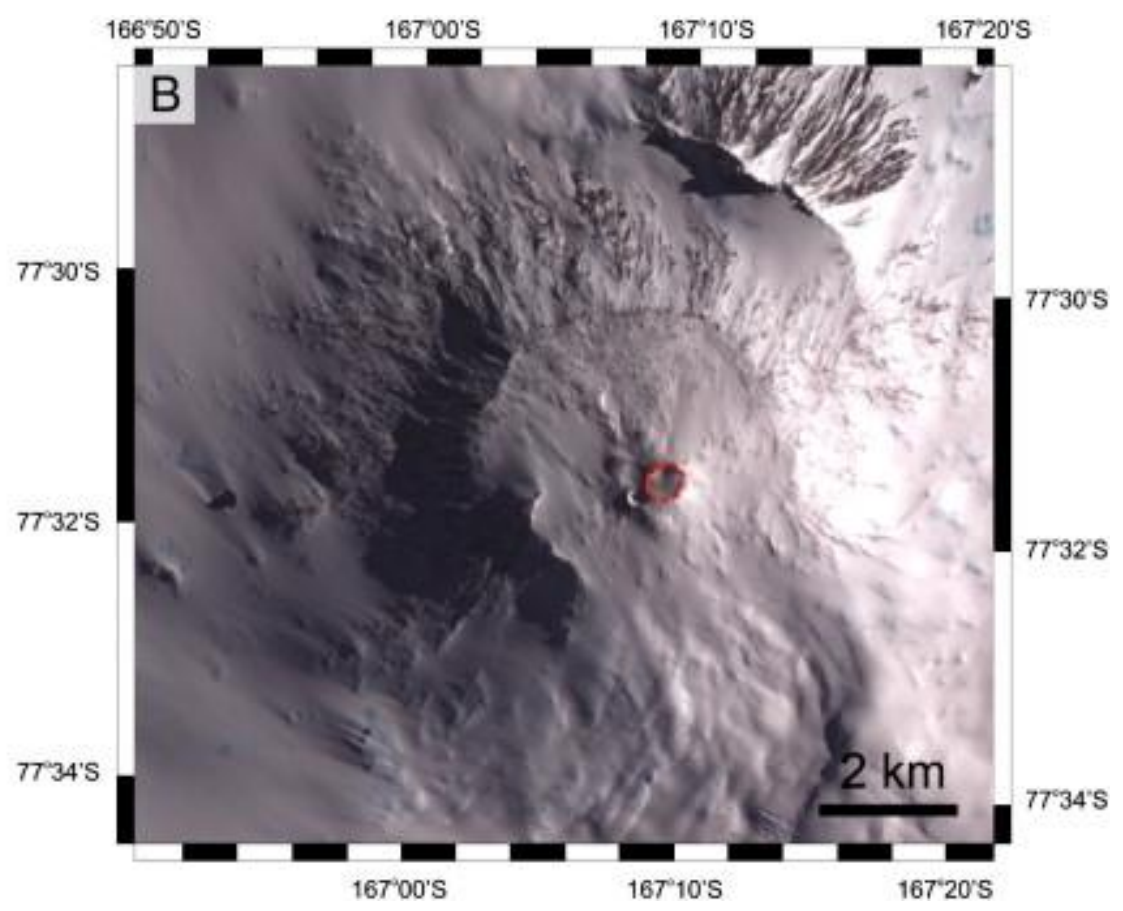

Fig. 1. A) The location of Mount Erebus (Antarctica) and B) an ASTER VNIR image of the volcano, taken on the 13th January 2008, with the active crater highlighted (red dashed line).

The permanent lake (referred to in the recent literature as Ray's lake) is sometimes accompanied by an ephemeral lake (at Werner's fumarole). Construction of the volcano began around 1.3 million years ago and is associated with crustal thinning and a possible mantle plume. The arid, polar climate in which the volcano is situated suppresses cloud cover and, coupled with the volcano's constant activity, makes Mount Erebus an excellent target for developing space-based thermal monitoring techniques of active volcanoes (e.g. [Harris et al., 1999], [Davies et al., 2008], [Wright and Pilger, 2008] and [Vaughan et al., 2010])

\subsection{Láscar volcano}

Láscar $\left(23^{\circ} 22^{\prime} \mathrm{S}, 67^{\circ} 44^{\prime} \mathrm{W}, 5592 \mathrm{~m}\right)$ is a young $(<50$-ka-old; Matthews et al., 1997) compound stratocone situated in the Chilean Altiplano to the East of the Salar de Atacama (Fig. 2). It is built from porphyritic andesites and dacites (Matthews et al., 1994). Historical activity is recorded back to 1848 (Gardeweg et al., 1994). The high and arid environment is associated with limited cloud, vegetation, snow and ice cover, thus making Láscar a very suitable terrain for geological remote sensing (de Silva and Francis, 1991). These environmental factors, coupled with Láscar's persistent degassing and frequent small-tomoderate explosive eruptions, have favored numerous remote sensing studies of Láscar volcano over the past quarter century (e.g. [Francis and Rothery, 1987], [Oppenheimer et al., 1993], [Wooster, 2001] and [Pavez et al., 2006]). 

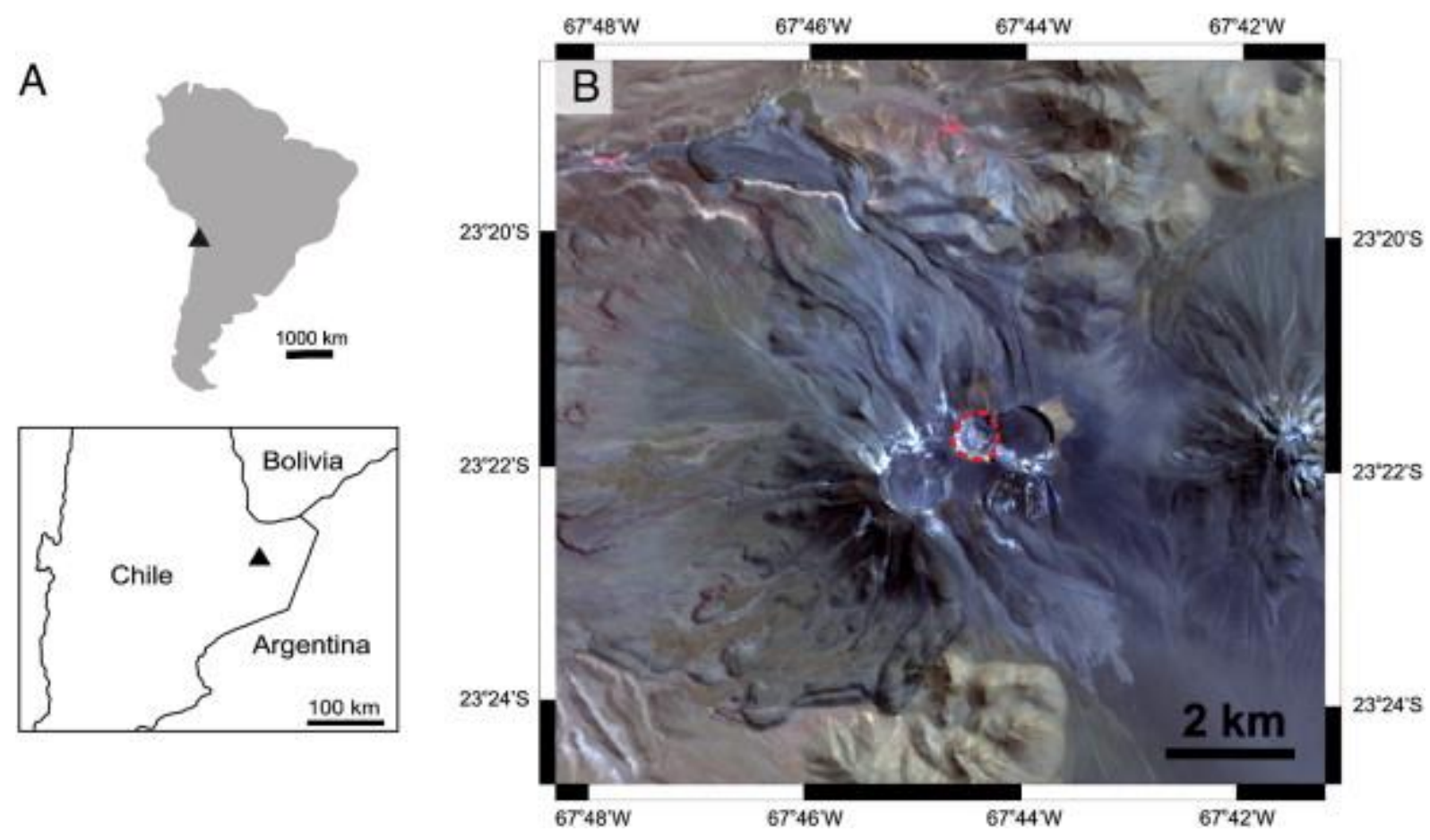

Fig. 2. A) The location of Láscar volcano (Chile) and B) an ASTER VNIR image of the volcano, taken on the 2nd April 2009, with the active crater highlighted (red dashed line).

\section{ASTER and data processing}

The ASTER sensor, launched onboard the Terra satellite, has been acquiring multispectral images of the Earth's surface for just over a decade. The imaging wavebands of this sensor fall into three spectral regions: i) the visible and near-infrared (VNIR), with four channels from 0.52 to $0.86 \mu \mathrm{m}, 15 \mathrm{~m}$ spatial resolution and stereoscopic viewing capability, ii) the short-wave infrared (SWIR), which has six channels from 1.6 to $2.43 \mu \mathrm{m}$ and $30 \mathrm{~m}$ spatial resolution, and iii) five channels in the thermal infrared with $90 \mathrm{~m}$ spatial resolution (Yamaguchi et al., 1998). Acquisition of SWIR data ended in early 2008 due to degradation of the detector cooler system. ASTER scenes are available at various processing levels, including raw at-sensor radiance values (L1A) as well as geometrically and radiometrically corrected sensor radiance values (L1B), which can be used to derive level 2 data products, such as atmospherically corrected surface radiance or surface temperature and emissivity.

This study uses the TIR at-surface radiance data product (AST_09T). These scenes were visually scrutinized for the presence of clouds and discarded if cloud formations were situated over the volcano. The images were then converted into land surface temperatures using the Normalized Emissivity Method (NEM) (Realmuto, 1990) using a maximum emissivity value of 0.97 . The resulting surface temperature estimates are dependent, among other factors, on seasonal and diurnal cycles as well as potential volcanic activity. To suppress non-volcanic variations through time we first calculate the background temperature, $\mathrm{BT}_{\mathrm{k}}$, as follows:

$$
B T_{k}=\sum_{n=1}^{n} T_{i, k} / n \text { where } i \in \beta_{k}
$$


where $T_{i, k}$ is a pixel temperature and $n$ is the number of pixels in the background area $\beta_{k}$ for the ith pixel in the kth scene. The background temperature is therefore the average

temperature of pixels within the background area. A temperature above background, $\Delta \mathrm{T}$, is found by subtracting the background temperature from a given pixel:

$\Delta T i, k=T i, k-B T k$.

Pixels close to background temperature will have low $\Delta \mathrm{T}$ values while volcanically heated pixels will be represented by positive $\Delta \mathrm{T}$ anomalies.

\subsection{Background areas}

As stipulated in Eq.(1) a background area is required to calculate a background temperature. Land surface temperatures are not homogenous. Therefore the size, shape and location of the background area will affect the background temperature. In previous studies these areas have ranged in size and location from a few pixels that are juxtaposed to anomalous regions, to $50 \times 50$ pixel arrays situated on neighboring topographic peaks (e.g. [Ramsey and Dehn, 2004], [Pieri and Abrams, 2005], [Carter et al., 2008] and [Vaughan et al., 2010]).

To demonstrate the potential sensitivity of background temperatures to the location of the background area we defined a square-shaped sample area $(10 \times 10$ pixels $)$ and moved it through 16 different, non-overlapping locations around the center of volcanic activity (Fig. 3). A background temperature was calculated for 16 such footprints for each scene. We then repeated this procedure for all scenes in the data set.
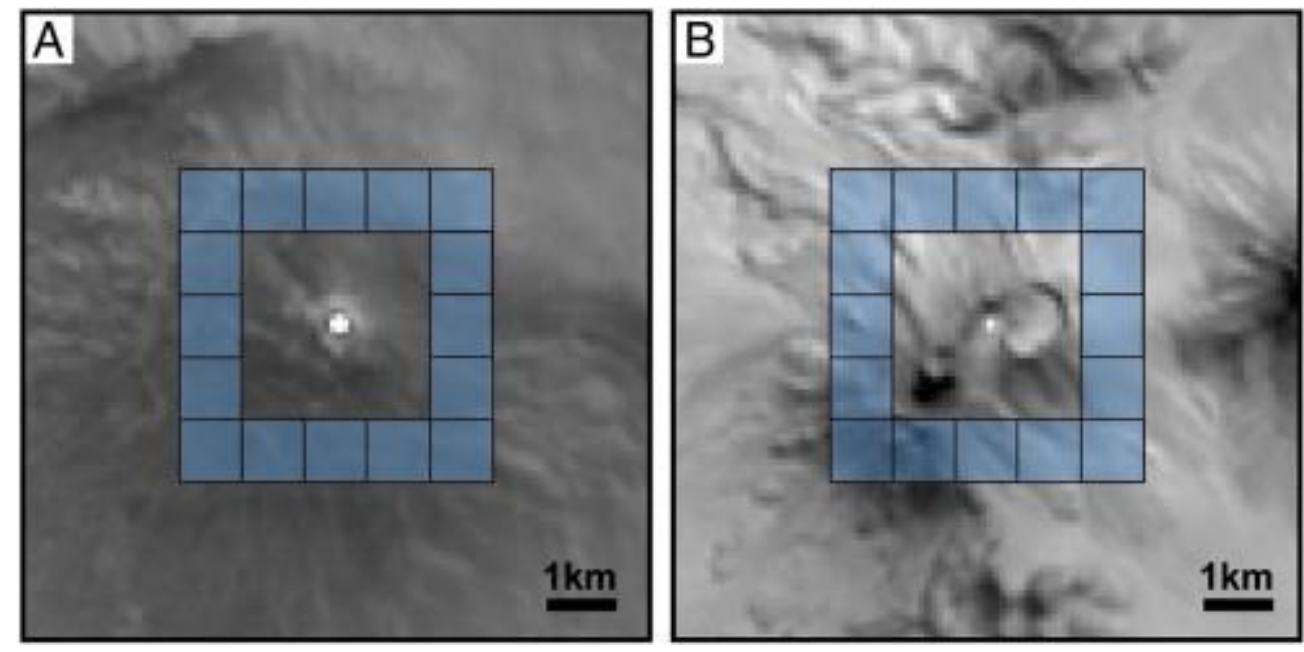

Fig. 3. The box-shaped areas used to sample background temperatures at both A) Erebus and B) Láscar. The boxes are 10 pixels (i.e. $900 \mathrm{~m}$ ) in length. North is up in both images.

With the exception of gas/aerosol plumes, reported volcanic activity is constrained within the active crater at both volcanoes. The sample areas are always situated at least 15 pixels (i.e. $1.35 \mathrm{~km}$ ) beyond the crater center. Inspection of temperature images reveals that the plumes have negligible thermal influence at such distances. In the presence of significant $\mathrm{SO}_{2}$ in the plume the NEM algorithm is still capable of producing reliable temperature retrievals due to automatic selection of the most appropriate band (e.g. in this case either ASTER band 13 or 
14, both of which avoid $\mathrm{SO}_{2}$ absorption features). The background temperatures recorded by each of the footprints can therefore be considered as non-volcanic.

The range (i.e. absolute difference between minimum and maximum) of background temperatures for the 16 grids was calculated on a scene by scene basis and plotted for a) Erebus and b) Láscar throughout the 2000-2009 time series (Fig. 4). This provides an indication of the sensitivity of a background temperature to the location of the background area. Nighttime scenes (black crosses - Fig. 4) tend to display a limited range in sample temperatures (i.e. means of $6.7^{\circ} \mathrm{C}$ at Erebus and $4.7^{\circ} \mathrm{C}$ at Láscar). This indicates that they are less sensitive to the location of the background area than the daytime scenes (red squares Fig. 4) which have mean ranges of $12.2^{\circ} \mathrm{C}$ at Erebus and $26.3{ }^{\circ} \mathrm{C}$ at Láscar. The maximum range in background temperatures is $18.9^{\circ} \mathrm{C}$ at Erebus and $34.0^{\circ} \mathrm{C}$ at Láscar. Hence there is a significant dependence of the background temperature on the location of the background area at both volcanoes, especially during the daytime. We interpreted this dependence as being predominantly due to preferential solar heating arising from variations in slope, aspect and solar azimuth at the time of image acquisition.
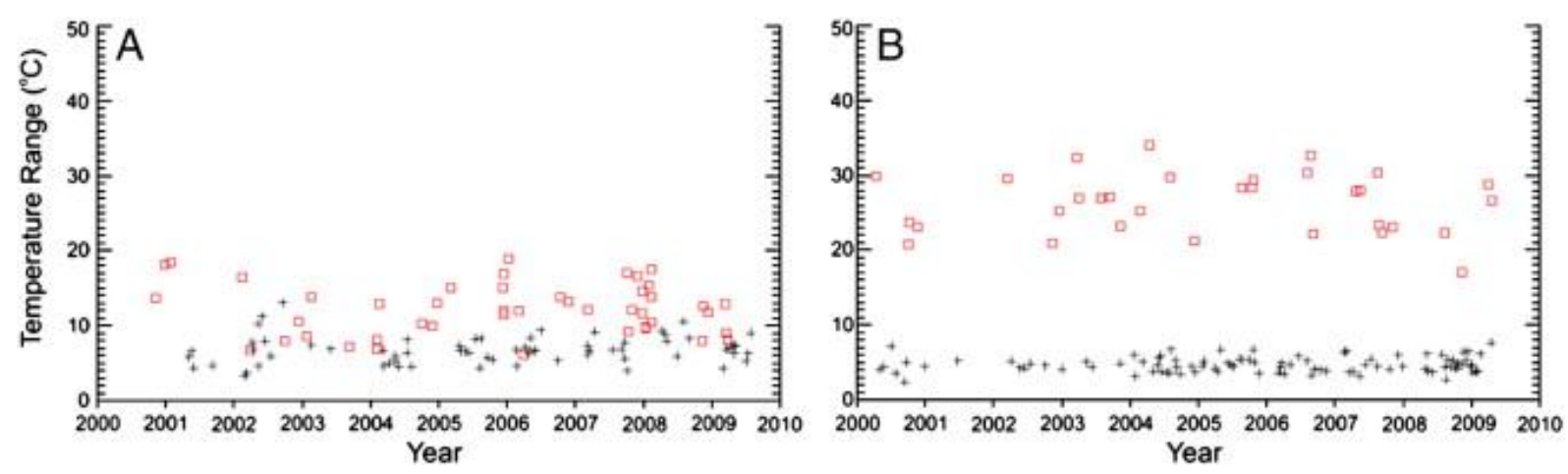

Fig. 4. The range in box sample temperatures at A) Erebus and B) Láscar. Red squares and black crosses symbolize daytime and nighttime scenes, respectively.

The sensitivity to diurnal effects as a result of slope aspect can be mitigated by defining the background area as an annulus around the active crater (as opposed to the square regions displayed in Fig. 3). Such a background will act to balance out topographically driven thermal heterogeneities and therefore stabilize background temperature estimates, even during the day. To define a ring-shaped area it is necessary to assign appropriate values for the inner and outer radius.

\subsubsection{Radius pairs}

To determine which inner and outer radius pair is most appropriate, sample temperatures were calculated for the area defined by all possible combinations of radius pairs that obey the following two criteria i) the inner radius may vary between 0 and 39 pixels, and ii) the outer radius may vary between 1 and 40 pixels but must be larger than the inner radius. This produces a total of 820 separate ring sample temperatures for each scene

To select the optimum radius pairs we impose two constraints. The first is based on the assumption that a radial profile of temperatures will tend to decrease monotonically toward the active crater due to topographic effects up until the point at which that profile passes 
through a volcanically heated area. The coldest ring temperature will therefore provide the best estimate of the non-volcanic (i.e. background) temperature in the active crater. The second constraint is that the total area of the background ring should be sufficiently large to smooth out unrepresentative pixel temperatures (e.g. due to the presence of undetected clouds and/or volcanic products, etc.). We define 'sufficiently large' as an area of at least 400 pixels based on the suggested size of a standardized array given by Vaughan et al. (2010). The background temperatures are not sensitive to this minimum size constraint, as shown below.

To validate the first constraint we calculated ring sample background temperatures for neighboring, inactive volcanic peaks (i.e. Aguas Calientes for Láscar and Mount Bird for Erebus). The deviation of each ring sample from the minimum ring sample was then calculated on a scene by scene basis to locate the coldest annular regions and to facilitate comparisons through time. The average deviation of ring samples from minimum was then calculated for all scenes in order to provide a metric that indicates by how much a given radius pair will tend to deviate from the coldest sample temperature (Fig. 5).
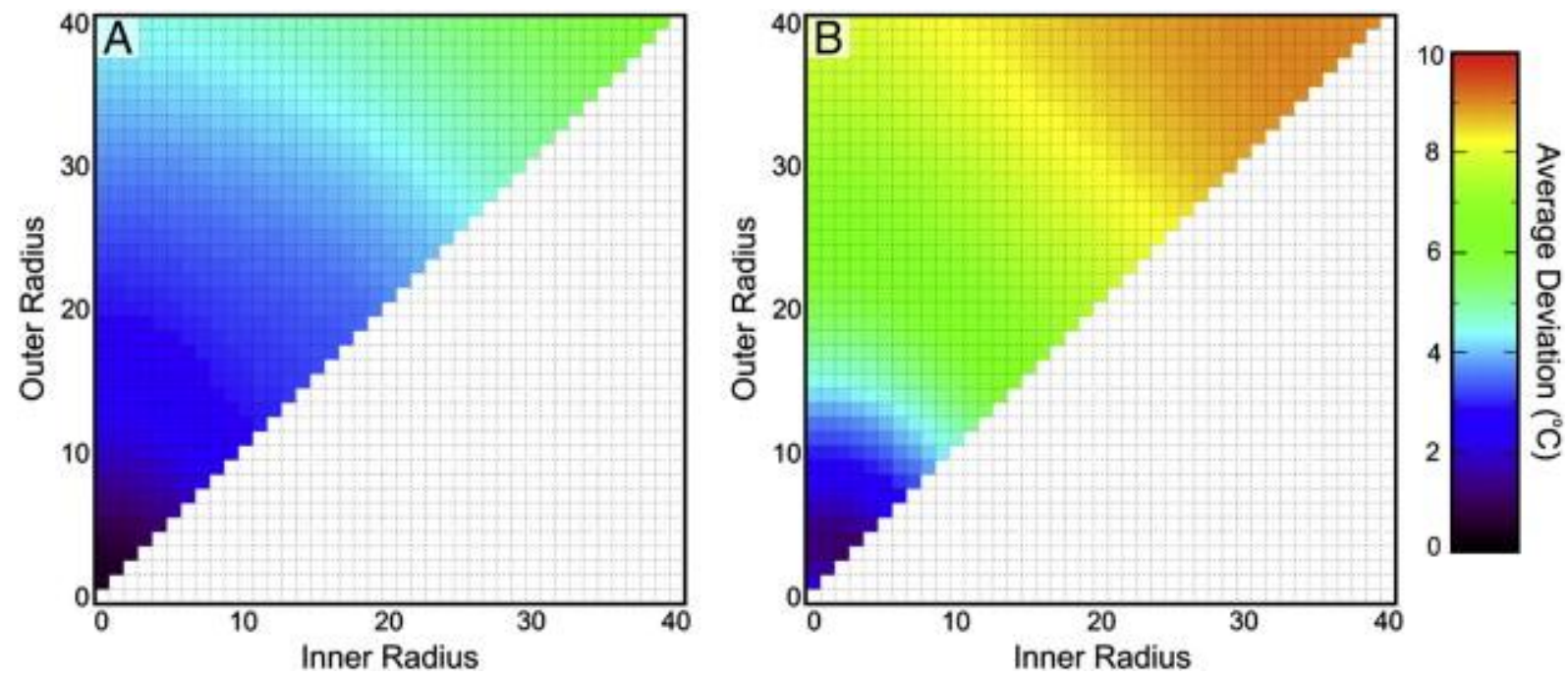

Fig. 5. Average deviation of ring sample temperatures from the minimum ring sample temperature for neighboring, non-active topographic peaks at A) Mt. Bird (Antarctica) and B) Aguas Calientes (Chile).

As expected, ring temperatures tend to be coldest at the top of these peaks (i.e. low radii values) and to warm up progressively down slope (i.e. warmer temperatures correspond to higher radii values). Aguas Calientes displays greater thermal contrast on average between minimum and maximum ring temperatures at this scale (i.e. average range of $\sim 9^{\circ} \mathrm{C}$ at Aguas Calientes and $\sim 6{ }^{\circ} \mathrm{C}$ at Mount Bird). This is presumably due to the more pronounced relief at Aguas Calientes as well as the stronger thermal heterogeneity in daytime land surface temperatures on the Altiplano in comparison to Ross Island.

Volcanic heating can clearly perturb a temperature gradient, with the active region becoming significantly warmer than the surrounding area. The average deviation of ring sample temperatures from minimum is calculated for a) Erebus and b) Láscar (ig. 6. .). Areas close to the active crater (i.e. low radii values) tend to be relatively hot. The coolest regions are situated fairly close to the active peak (i.e. the blue-black arc shaped region). Regions that are further out still (i.e. high radii values) tend to be relatively warm as they are situated at lower altitude. 

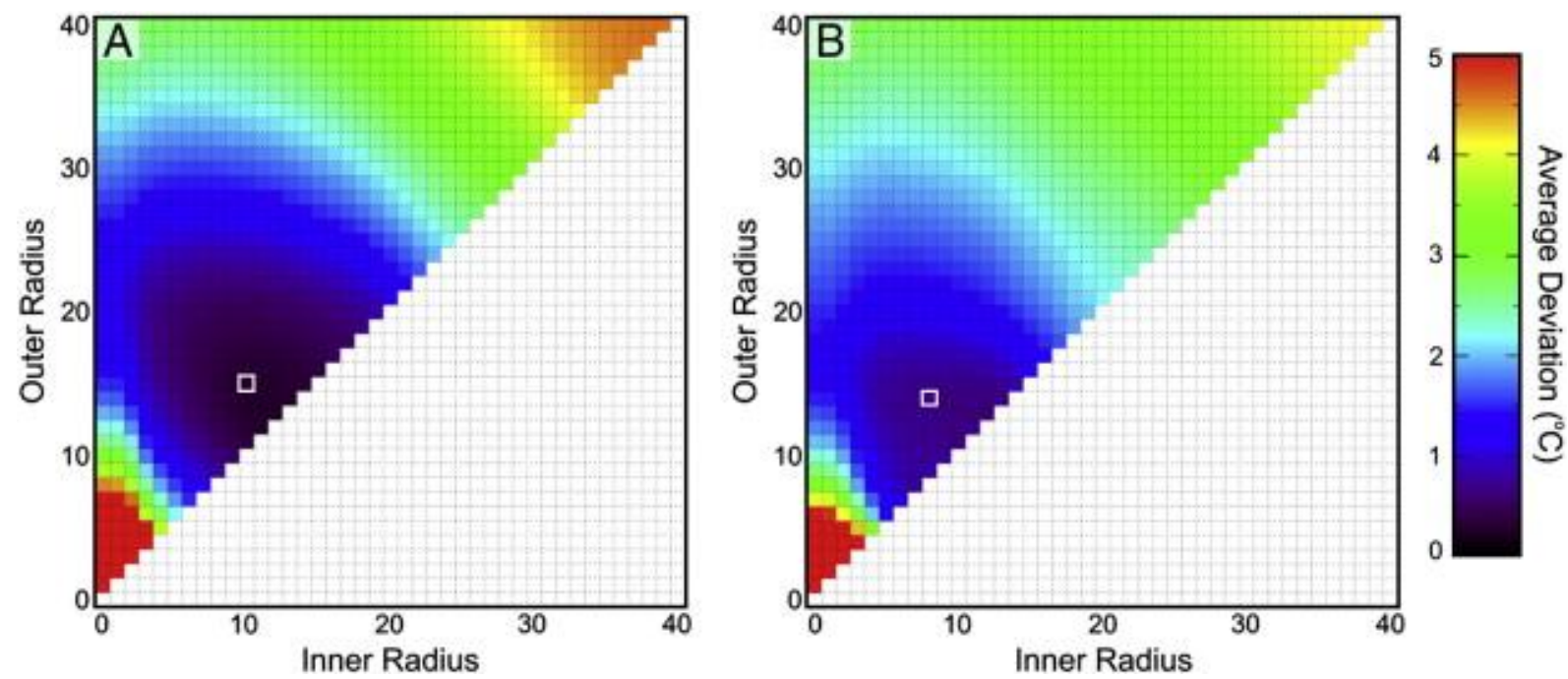

Fig. 6. Average deviation of ring sample temperatures from the minimum for A) Erebus and B) Láscar volcano. Optimum radius pairs are highlighted with a white square outline.

The optimum radius pairs (i.e. coldest average ring which is at least 400 pixels in size) have inner and outer radii of i) 10 and 15 pixels at Erebus, and ii) 8 and 14 pixels at Láscar. They are highlighted using a white square outline in Fig. 6. These optimum background areas are displayed for both A) Erebus and B) Láscar in Fig. 7.
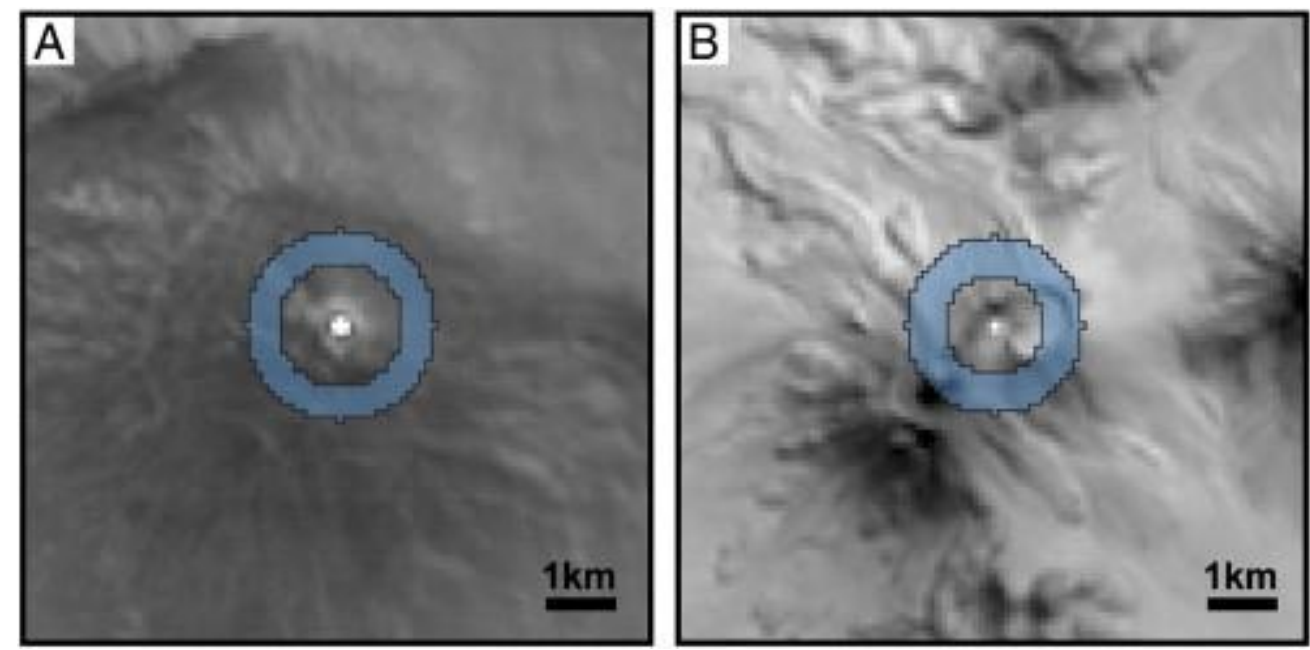

Fig. 7. The size and location of optimum ring-shaped background areas at both a) Erebus and b) Láscar. North is up in both images.

Comparison between the optimum ring temperatures and the minimum ring temperatures on a scene by scene basis reveals that their average difference is $0.29 \pm 0.25{ }^{\circ} \mathrm{C}$ at Erebus and $0.68 \pm 1.0^{\circ} \mathrm{C}$ at Láscar. The optimum background temperatures are therefore generally insensitive to the minimum size constraint. Even so the implementation of this constraint will 
yield a more reliable background temperature estimate. Furthermore, the fact that background areas are allowed to adapt to each volcano represents a crucial step toward facilitating the use of this technique on a global basis.

\subsection{Background temperatures}

Having defined the optimum size, shape and location of a background area it is possible to calculate the background temperature for a given scene (i.e. Eq.(1)). The background temperature is calculated for all scenes at both a) Erebus and b) Láscar (Fig. 8).

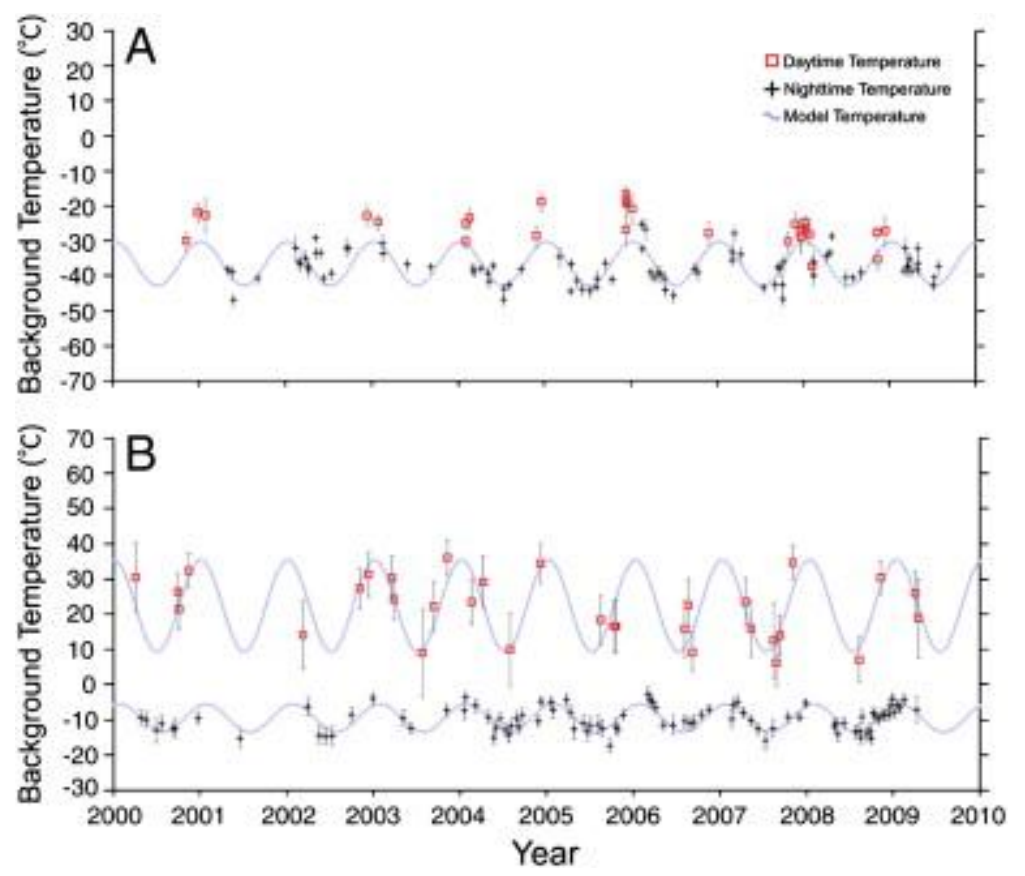

Fig. 8. The background temperatures of A) Erebus and B) Láscar volcanoes from 2000 to 2009. Red squares and black crosses denote daytime and nighttime images, respectively. Error bars are one standard deviation.

Comparison of background temperatures highlights climatic differences at both volcanoes. The background temperatures tend to be significantly colder at Erebus (Fig. 8A) then at Láscar (Fig. 8B), ranging from approximately -50 to $-20^{\circ} \mathrm{C}$ at the former and -10 to $40{ }^{\circ} \mathrm{C}$ at the latter. However, the disparity between daytime and nighttime temperatures is more pronounced at Láscar. This is due to the fact that the volcano is situated at subtropical latitudes on a desert Altiplano, while Erebus is situated at polar latitudes and spends the majority of the year in either continuous darkness or continuous light, with a 24 hour diurnal cycle only occurring during the Austral spring and autumn. A recent independent field measure taken from within the active crater on the 13th December 2005 (Vaughan et al., 2010) found a background temperature value (i.e. $-15.8^{\circ} \mathrm{C}$ ) that is comparable to our concurrent value of $-19.0^{\circ} \mathrm{C}$ measured from space. 
The ASTER sensor is in a sun-synchronous orbit therefore images of a given point on the Earth's surface are acquired within a fixed time window for ascending and descending orbits. Image acquisitions of Erebus occur at either 14:05 +/-30 or 20:32 +/-20 UTC, while images of Láscar are acquired at either 14:51 +/-10 or 03:20 +/-10 UTC. The benefit of taking images at the same time of day or night is that diurnal variations in temperature are suppressed. Meteorological effects have also been minimized by screening out cloudy scenes. Seasonal effects are therefore the major influence on background temperatures in these time series. A reasonable model of this effect can be achieved through the use of a sinusoidal function (Eq. (3)).

$B T^{*}=\mathrm{a} \sin (\omega \mathrm{t}+\varphi)+\mathrm{c}$

where $\mathrm{BT}^{*}$ is the modeled background temperature, a, is the amplitude of seasonal temperature fluctuations, $\omega$ is angular frequency (i.e. $2 \pi$ per year), $t$ is time, $\varphi$ is the phase (i.e. onset of the seasons) and $\mathrm{c}$ is the point about which the function oscillates (i.e. approximately the average temperature of the time series). The model is justifiable because seasonal effects are predominantly controlled by a stable cyclic motion (i.e. the Earth revolving around the sun), that does not show significant perturbation over this time frame. Daytime and nighttime temperatures are modeled separately for Láscar although such a distinction is not made at Erebus as polar diurnal and seasonal cycles are somewhat synchronized. Models are fit using least-squares regression.

The mean absolute error from the model is less than $4.5^{\circ} \mathrm{C}$ for all data sets (Table 1). Láscar daytime scenes display the largest $\mathrm{BT}^{*}$ amplitude, indicating that they are the most susceptible to seasonal variations. The best fit is provided by Láscar night-time series. However, we observe that while Láscar day and night scenes should be in phase they are $\sim 100$ days apart. We attribute this discrepancy to the limited number of daytime scenes in this data set and correspondingly poorer constraint of the daytime model.

Table 1. The least-squares best fit of sinusoidal model parameters on background temperatures. Mean and maximum absolute errors are also provided.

\section{Data set Amplitude Vertical Offset Phase Mean|error| Max|error|}
$\left({ }^{\circ} \mathbf{C}\right)$
$\left({ }^{\circ} \mathrm{C}\right)$
(Days)
$\left({ }^{\circ} \mathbf{C}\right)$
$\left({ }^{\circ} \mathrm{C}\right)$

$\begin{array}{llllll}\text { Erebus (total) } & 6.23 & -36.5 & 42.4 & 3.7 & 13.7 \\ \text { Lascar (day) } & 13.03 & 22.4 & 175.2 & 4.45 & 9.6 \\ \text { Lascar (night) } & 4.01 & -9.5 & 67 & 1.68 & 3.9\end{array}$

\section{Anomalous volcanic temperatures}

Although the ASTER sensor is particularly well suited to calculating terrestrial temperatures, existing metrics that describe volcanic temperatures estimates from space are limited in the sense that they do not identify all anomalous pixels. Instead they measure either the single hottest pixel temperature (e.g. [Ramsey and Dehn, 2004], [Pieri and Abrams, 2005], [Vaughan and Hook, 2006], [Carter et al., 2008] and [Vaughan et al., 2008]), which may undergo a sub-pixel component analysis (e.g. [Pieri and Abrams, 2005] and [Hirn et al., 
2008]), or they measure a crater-averaged temperature (Vaughan and Hook, 2006). The maximum temperature above background has arguably proved the most insightful metric so far. It has been used to detect new high temperature features, such as fumaroles and lava domes (e.g. [Ramsey and Dehn, 2004] and [Vaughan et al., 2008]) as well as to describe cooler materials such as pyroclastic flow deposits and lahar deposits (e.g. [Ramsey and Dehn, 2004] and [Carter et al., 2008]). As mentioned previously, however, a significant drawback of measuring just the maximum pixel temperature is that it does not provide any spatial information regarding anomalies (Carter et al., 2008). For example, the same maximum temperature value could correspond to a small isolated anomaly on one date and a larger widespread anomaly on another. We propose that an improved measure of volcanic activity would account for all anomalous pixels. To create such a metric it is necessary first to define an appropriate threshold for thermally anomalous pixels.

\subsection{Anomalously hot pixels}

For a pixel to be considered anomalously hot it must exceed the background temperature by a significant amount. Such a threshold can be determined by calculating the natural variability of $\Delta \mathrm{Ts}$ within a dataset and then defining a statistical limit above which background $\Delta \mathrm{Ts}$ are not expected to exceed. To achieve such a goal it is necessary to convert individual $\Delta$ Ts into a measure of variability. We use $\mathrm{z}$-scores, $\mathrm{z}_{\mathrm{i}, \mathrm{k}}$, for this purpose, given by:

\section{$Z i, k=\Delta T i, k / \sigma k$}

where $\Delta \mathrm{T}_{\mathrm{i}, \mathrm{k}}$ is a pixel temperature above background and $\sigma_{\mathrm{k}}$ the standard deviation of the background temperature, and subscripts denote ith pixels in kth scenes. A z-score is therefore a normalized measure of deviation from the background temperature. The background (i.e. mean) temperature is represented by a z-score of zero. A pixel temperature that is one standard deviation above or below this mean will have a z-score of 1 or -1 , respectively.

A frequency distribution (i.e. histogram) of z-scores can be converted into a probability density function (PDF) by normalizing appropriately. We determine a PDF of z-scores for all scenes at A) Erebus and B) Láscar that were acquired by i) day and ii) night (Fig. 9). These PDFs represent the expected deviation of background pixels from the background temperature in units of standard deviations. 

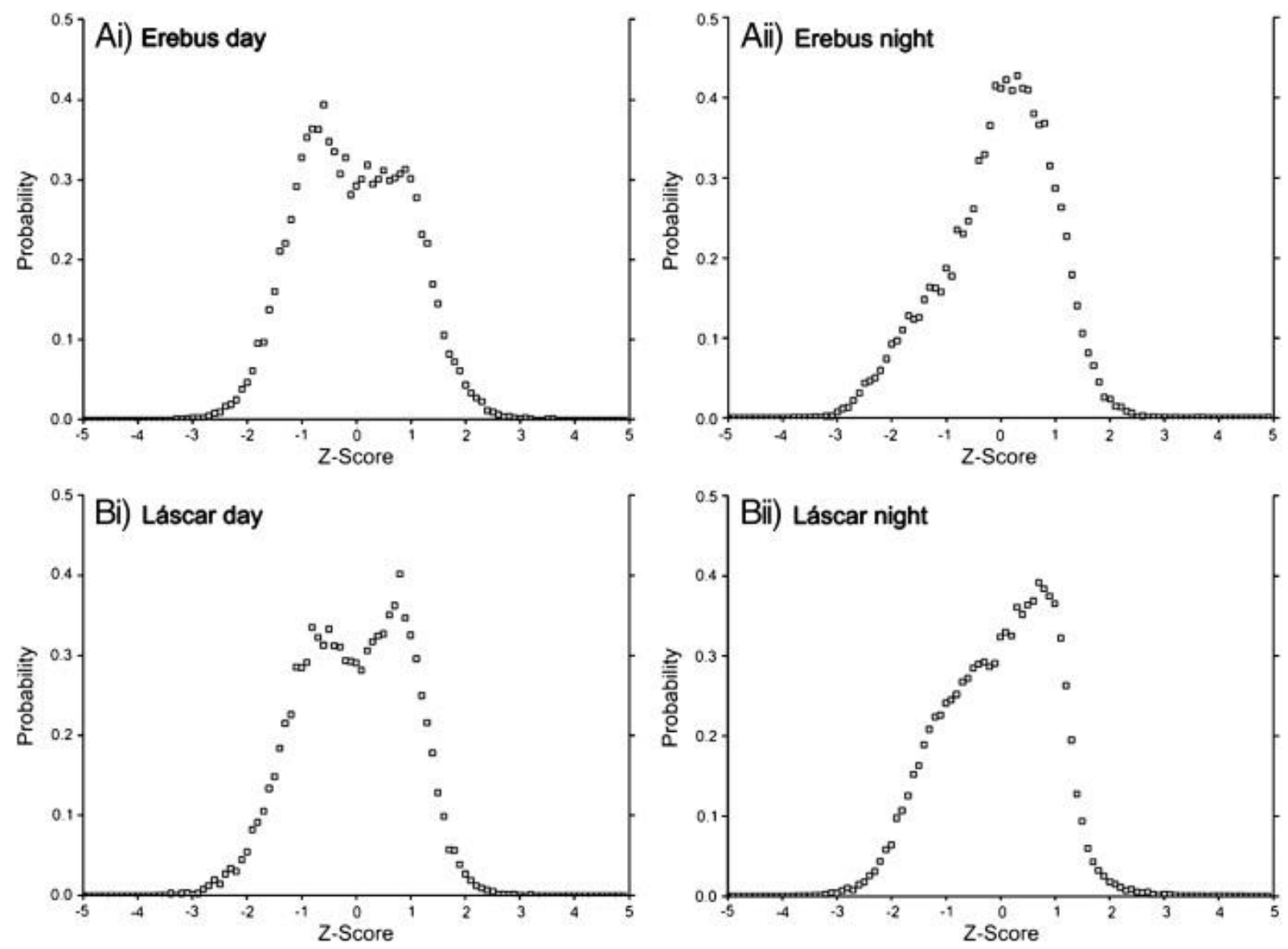

Fig. 9. Probability density functions of background z-scores at A) Erebus, B) Láscar during i) the day and ii) the night, calculated using all scenes in each dataset.

Daytime distributions are somewhat bimodal, this is presumably due to the amalgamation of two principal temperature distributions which correspond to i) surfaces on the volcanic edifice that are more exposed to solar radiation and ii) surfaces that are in shadow. Nighttime distributions are unimodal at both volcanoes and quite strongly asymmetric at Láscar, with the mode (i.e. peak probability) occurring distinctly above the mean. This may be due to more efficient heat loss from relatively warm areas, which consequently bunches together pixel temperatures that are above the mean.

We can see from these PDFs that the vast majority of pixel temperatures will not exceed the background temperature by more than two standard deviations. In particular, $99 \%$ of z-scores are below two at Láscar (during the day or night) as well as for the Erebus night time series, while $98 \%$ of scenes have z-scores below two for the Erebus daytime series.

An anomaly could be defined on a scene by scene basis by using a given z-score threshold. However, as variations in background temperatures are seasonally dependent (i.e. error bars in Fig. 9), it follows that such a measure of anomaly would also be seasonally dependent. To introduce a more consistent measure of thermal anomaly through time we select the maximum standard deviation of background temperatures within a time series, $\sigma_{\max }$, and use twice its value as a threshold. A pixel is therefore considered to be anomalous if it satisfies the condition outlined in Eq. 5.

$\Delta T i, k-2 \sigma_{\max }>0$ 
This provides a fixed criterion for detecting anomalies in a given time series and a very low false alarm rate. The maximum standard deviation of background temperatures at Erebus and Láscar are 4.9 and $11.7^{\circ} \mathrm{C}$ during the day and 2.4 and $3.6^{\circ} \mathrm{C}$ during the night, respectively. Temperatures above background would therefore be considered as anomalously hot if they exceeded $9.8^{\circ} \mathrm{C}$ or $23.4{ }^{\circ} \mathrm{C}$ for daytime series, and $4.8^{\circ} \mathrm{C}$ or $7.2^{\circ} \mathrm{C}$ for nighttime series at Erebus and Láscar, respectively. We note that variability in daytime temperatures hinders subtle thermal anomaly detection. Nonetheless, the metric proposed here accounts for the natural fluctuation within a dataset and describes a statistical limit beyond which we identify volcanogenic heating.

\subsection{The spatial extent of thermal anomalies}

Given this quantification of 'anomalously hot' pixels it is possible to determine the overall size of anomalous areas by simply counting the relevant pixels. In order to focus on local volcanic effects the target area for such an anomaly search was defined as the circular region within the background area. The frequency distributions of anomalous temperatures can also be obtained by binning pixels into given temperature ranges. This discriminates, for example, large cool areas from small hot areas, thus facilitating the interpretation of thermal anomalies. Here, we classify three anomaly classes as follows: i) $\operatorname{cool}\left(\Delta \mathrm{T}<30^{\circ} \mathrm{C}\right)$, ii) moderate $\left(30<\Delta \mathrm{T}<60^{\circ} \mathrm{C}\right)$ and iii) hot $\left(\Delta \mathrm{T}>60^{\circ} \mathrm{C}\right)$. We avoid defining a larger number of narrower thermal regions at present given that it may not be appropriate at this spatial resolution.

\subsubsection{SWIR anomalies}

Nighttime short-wave infrared anomalies are also calculated using an analogous background value and standard deviation threshold, although in this case to differentiate from sensor noise as opposed to seasonal or diurnal affects. We did not analyze daytime SWIR images as solar irradiation tends to significantly hinder anomaly detection at these wavelengths. It is important to note that saturation occurs frequently in the SWIR wavebands over these targets (i.e. in $84 \%$ of Erebus scenes and $48 \%$ of Láscar scenes). This arises because the upwelling radiation reaching the satellite sensors often exceeds the dynamic ranges of the various ASTER SWIR detectors and therefore limits the extent to which the SWIR channels can be used for quantitative measurements. As such we limit classification of pixels within SWIR scenes to the binary case of being either anomalous or not anomalous.

\section{Results}

\subsection{Maximum temperatures above background}

A series of maximum pixel temperatures above background are given for a) Erebus and b) Láscar (Fig. 10). The Erebus time series (Fig. 10A) reveals considerable scatter in both daytime and nighttime scenes and no clear secular trends. On the other hand, Láscar displays a more coherent temporal pattern (Fig. 10B) which appears to show pronounced changes in intensity with respect to most of the reported erupted episodes at Láscar ( [Bulletin of the Global Volcanism Network. Láscar., 2000], [Bulletin of the Global Volcanism Network. Láscar., 2003], [Bulletin of the Global Volcanism Network. Láscar., 2004], [Bulletin of the Global Volcanism Network. Láscar., 2005], [Bulletin of the Global Volcanism Network. Láscar., 2006] and [Bulletin of the Global Volcanism Network. Láscar., 2007]). The reported mid-points of these episodes are highlighted as triangles in Fig. 10B. 


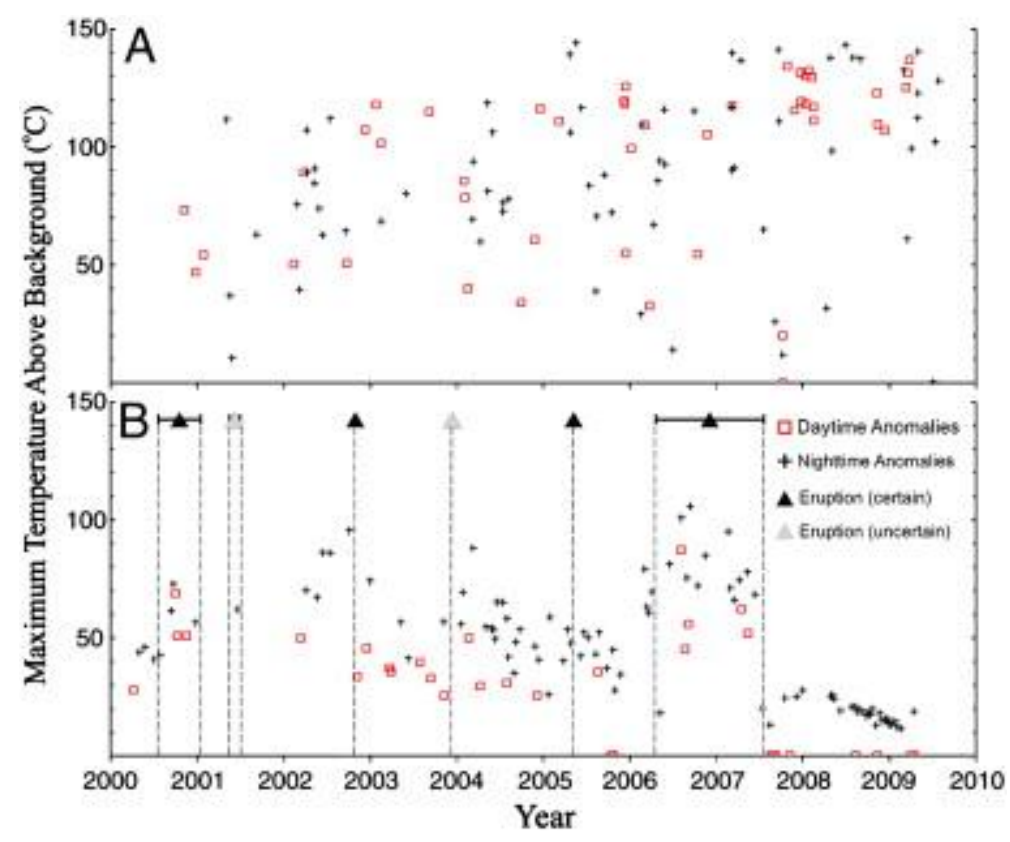

Fig. 10. Maximum temperatures above background for A) Erebus and B) Láscar. Red squares and black crosses denote daytime and nighttime images, respectively. The mid-point of eruptive episodes is denoted using a triangle symbol, the color of which indicates either high (i.e. black) or lesser (i.e. gray) levels of reported certainty in the occurrence of that eruption. When the start and stop date of an eruptive episode differ they are joined by a horizontal bar.

The scatter at Erebus appears to be incongruent with the limited variation in thermal output from the lava lake that has been observed using both long term orbital data (Wright and Pilger, 2008) and field thermography ( [Calkins et al., 2008] and [Oppenheimer et al., 2009]). There are several potential contributing factors to this scatter. One such influence is the dependence of pixel temperatures on the fractional area of the lake within a given pixel. The size of the lake during this time period varied between $\sim 700$ and $1400 \mathrm{~m}^{2}$ ( [Csatho et al., 2008] and [Calkins et al., 2008]) while each ASTER TIR pixels corresponds to an area of $\sim 8100 \mathrm{~m}^{2}$. The lake may therefore 'fit' completely within a single pixel or be divided between up to four pixels. The number of pixels within which the lava lake is imaged will influence the maximum temperature of a given scene. This dependency is modeled below (see Discussion) using a 3-component model of the lava lake system, with hot cracks, crust and non-volcanic background, to demonstrate that maximum pixel temperatures vary significantly as a function of the maximum proportion of the lava lake within a given pixel.

Other factors that may also create scatter in maximum pixel temperatures at Erebus include i) the concentration, composition and location of aerosols and gas plumes, ii) short time scale variations in radiative output from the lake due to pulsatory magma supply and gas emission, iii) the amount and temperature of spatter around the lake, iv) the disposition of other thermal anomalies within the Erebus crater (e.g. the ephemeral 'Werner' lava lake), v) the background temperature itself in the case that pixel saturation occurs, vi) meteorological effects; of which air temperature, relative humidity and wind speed might have an important control on the development of fumes, and vii) the viewing geometry; which is dependent on the nadir angle of the sensor at the time of acquisition (i.e. nadir varies between $+/-8.6$ in both data sets), the position of the anomaly within the swath and the topography of the target area. 
The maximum temperature series at Láscar displays a significant contrast in style. Temporal trends are discernable and appear associated with eruptive events. These trends include a) two eruptive precursors, namely i) a gradual increase before the 2002 eruption and ii) a gradual decrease followed by an increase before the 2006 eruption, b) syn-eruptive increases during the 2000 and 2006 eruptions as well as c) post-eruptive changes, with a brief increase after the 2003 eruption and sustained decrease after the 2006 eruption.

The onset of the first eruption in the Láscar time series occurs within 7 months of the launch of the ASTER sensor. Trends preceding this eruption are therefore unclear. However maximum temperatures are higher during the eruptive episode relative to pre-eruptive values. Few data were available for 2001, with only one suitable cloud-free scene available for that year. We thus have no data bearing on the eruptive episode reported to have occurred between 4th May and 6th July 2001 (Smithsonian Institution. Láscar Eruptive History).

The October 2002 eruptive episode consisted of several small explosions that produced ash plumes ranging in height from 300 to $1500 \mathrm{~m}$ above the crater rim (Bulletin of the Global Volcanism Network. Láscar., 2003). This episode was preceded by a progressive increase in maximum pixel temperatures above background (Fig. 10B). Lava dome growth and destruction have been associated with a number of Láscar's past eruptions but no dome was observed in the active crater throughout 2000-2002 (Bulletin of the Global Volcanism Network. Láscar., 2003). The increase in thermal output apparent from the ASTER time series is therefore likely to represent an increase in the temperature and/or flux of gas emission. Increases in fumarolic activity have also been observed before explosive eruptions at other stratovolcanoes (e.g. July 1985 at Nevado del Ruiz, Colombia [Scientific Event Alert Network. Nevado del Ruiz., 1985], July 1995 at Soufrière Hills, Montserrat [Bulletin of the Global Volcanism Network. Soufrière Hills., 1995], and May 2010 at Bezymianny, Kamchatka [Smithsonian Institute. Bezymianny Weekly Reports. May, 2010]).

Following the October 2002 eruption the active crater collapsed by several tens of meters, producing a deep, steep depression roughly $200 \mathrm{~m}$ in diameter and $200 \mathrm{~m}$ deep (Bulletin of the Global Volcanism Network. Láscar., 2003). Fumarolic activity continued after this time and was punctuated by the occurrence of a $400 \mathrm{~m}$ high, gray colored plume in December 2003 (Bulletin of the Global Volcanism Network. Láscar., 2004). No thermal precursors are apparent before this eruption. The brief peak in maximum temperatures after the event perhaps indicates that a temporary, post-eruptive increase in fumarolic activity occurred. Such an increase could be the result of decompression of magma remaining in the upper conduit following the expulsion of magma during the eruption, facilitating both the exsolution and transport of volatiles to the surface. Alternatively it may indicate that an active lava dome was exposed at the surface at that time.

Local residents (15-60 km from the volcano) did not report any earthquakes or explosions in relation to a Vulcanian eruption of May 2005. Nor do we observe any significant changes in maximum temperatures above background before, during or after this event. Nevertheless, an ash cloud was observed in AVHRR imagery and very fine ash fall was also reported in Salta (Argentina) $285 \mathrm{~km}$ SSE (Bulletin of the Global Volcanism Network. Láscar., 2005).

Field observations of the active crater in December 2005 (i.e. after the May 2005 eruption) revealed that the crater floor was no longer visible from the accessible (i.e. Southern) side of the crater rim, indicating that further subsidence had occurred (Bulletin of the Global Volcanism Network. Láscar., 2006). Maximum temperatures show a gradual decrease 
throughout this time (i.e. from May to December 2005) and may be related to crater collapse and an overall reduction in permeability in the upper conduit. Mechanisms for such permeability reduction include: i) bubble collapse of a foamy lava, ii) precipitation of hydrothermal minerals, iii) welding and fusion of the conduit walls, and iv) increases in the dynamic viscosity and strength of magma by cooling, degassing and crystallization (Matthews et al., 1997). This trend is analogous to the behavior described for the 1993 eruptive style (Oppenheimer et al., 1993), at which time decreases in conduit permeability and therefore fumarolic activity (as inferred from decreases in radiant flux measured by Landsat infrared bands) were shown to precede eruptive events. We note that it is possible that the collapse of the crater may also act to obscure some of the radiance emitted by the volcano from reaching the sensor in off-nadir scenes.

Here we also observe, for the first time, an increase in maximum temperatures (i.e. $\sim$ January to April 2006) following a gradual decrease as described above. It is not clear whether this represents a sudden increase in permeability, the emplacement of a lava dome or perhaps even an unreported eruption.

Maximum temperatures above background remain elevated throughout the April 2006-July 2007 eruptive period. This could reflect a period of elevated strong fumarolic activity or possibly effusion of a lava dome. No lava dome was observed during fieldwork at the active crater carried out by one of us (S. Murphy) on 10 December 2009 (Fig. 11), though the crater floor was still not visible from the Southern rim of the volcano at that time.

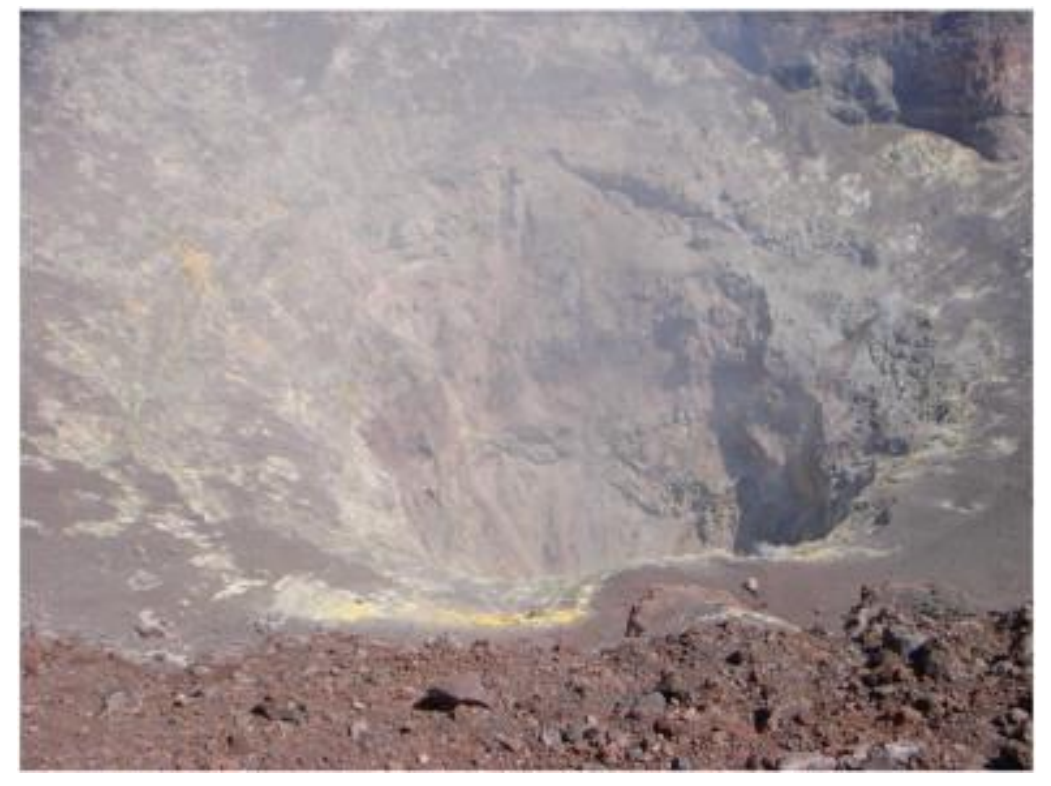

Fig. 11. The collapsed active crater of Láscar volcano as seen from the Southern rim on the 10th December 2009. A lava dome is not visible, however, neither is the crater floor due to local topographic relief.

After this final eruptive period (i.e. July 2006 onwards) maximum temperatures above background remained consistently low, with anomalies only being detected at night. A small increase in these maximum temperatures can be seen throughout the remainder of 2007. Following this a gradual decrease in maximum temperatures is observed until the end of the time series (i.e. 18th April 2009). We infer that fumarolic intensity was relatively low at this time, perhaps reflecting waning degassing of residual magma in the conduit. 


\subsection{The spatial extent of thermal anomalies}

The spatial extents of thermally anomalous regions for both a) Erebus and b) Láscar are displayed in Fig. 12. A separate scatter plot is used to display the size of i) low, ii) moderate and iii) high temperature anomalies, as well as iv) SWIR anomalies. Note the distinction between daytime and nighttime scenes.

A) Erebus

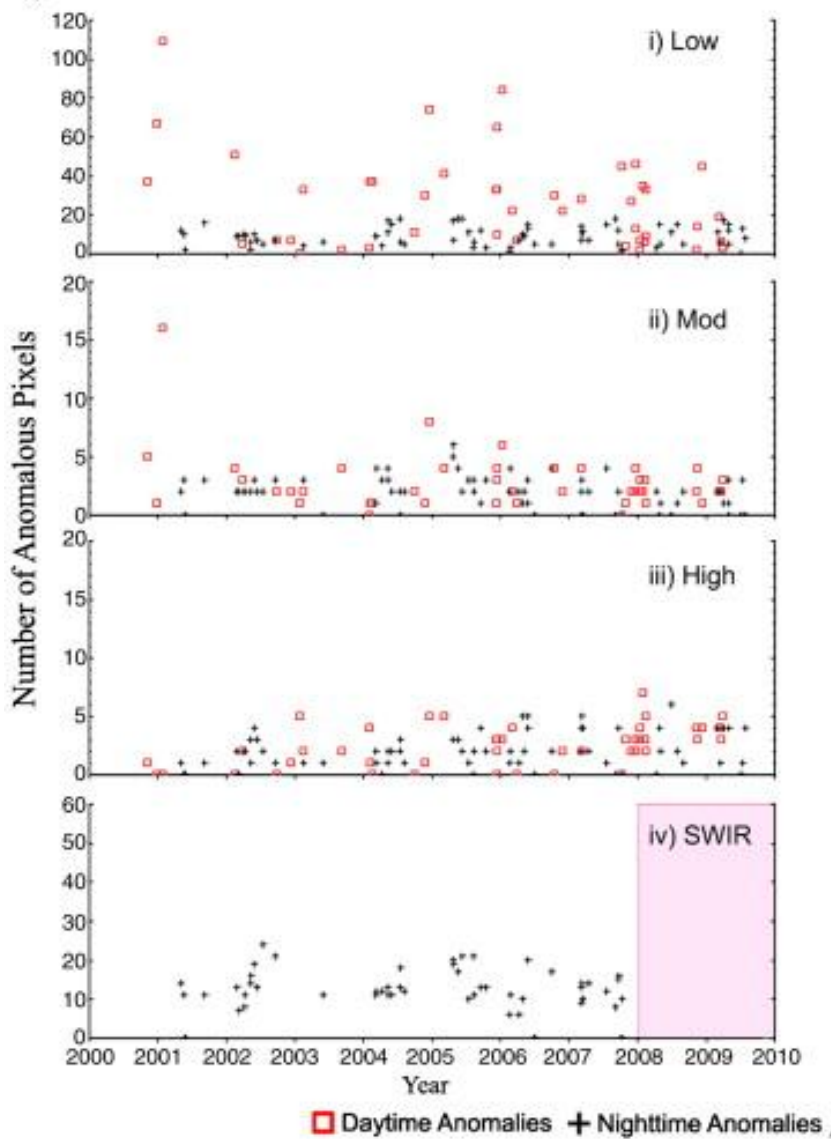

B) Láscar
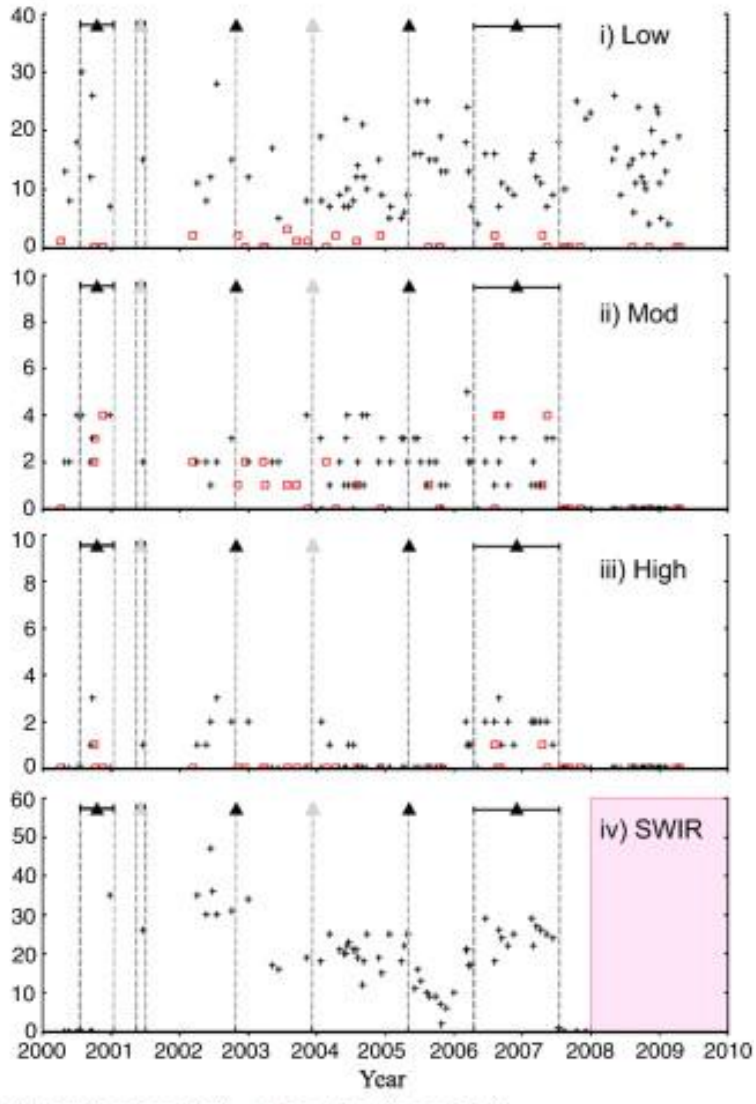

A Eruption (certain)

Eruption (uncertain)

Fig. 12. The size of thermal anomalies at A) Erebus and B) Láscar volcano. Distinction is made between i) low, ii) moderate and iii) high temperature anomalies, as well as iv) a SWIR anomaly series (interrupted in 2008 due to the ASTER SWIR system failure). Note that temperature and SWIR pixel sizes are not the same (i.e. 90 and $3 \mathrm{~m}^{2}$, respectively). Red squares and black crosses denote daytime and nighttime images, respectively.

\subsubsection{Erebus}

Low temperature anomalies at Erebus (Fig. 12A i) display a strong dependence on solar irradiation with peaks occurring during daylight hours. Comparison with VNIR scenes indicates that these low temperature anomalies often coincide with bare rock around the Erebus crater and to Sun facing rocks beyond the caldera edge (e.g. Fig. 13C). Ideally the background area would represent all the inactive surfaces in the target area (i.e. both snow and 
rock in this case). However, simply incorporating the exposed rocks around the crater rim into the background area is likely to produce unreliable background temperatures given that fumarolic activity up the inner crater walls and/or the presence of plumes can thermally contaminate such proximal regions. We do not attempt to fine tune the background selection methodology here but rather emphasize the caution required in interpretation of thermal anomalies and the value of comparing the anomaly maps with the original reflectance datasets.

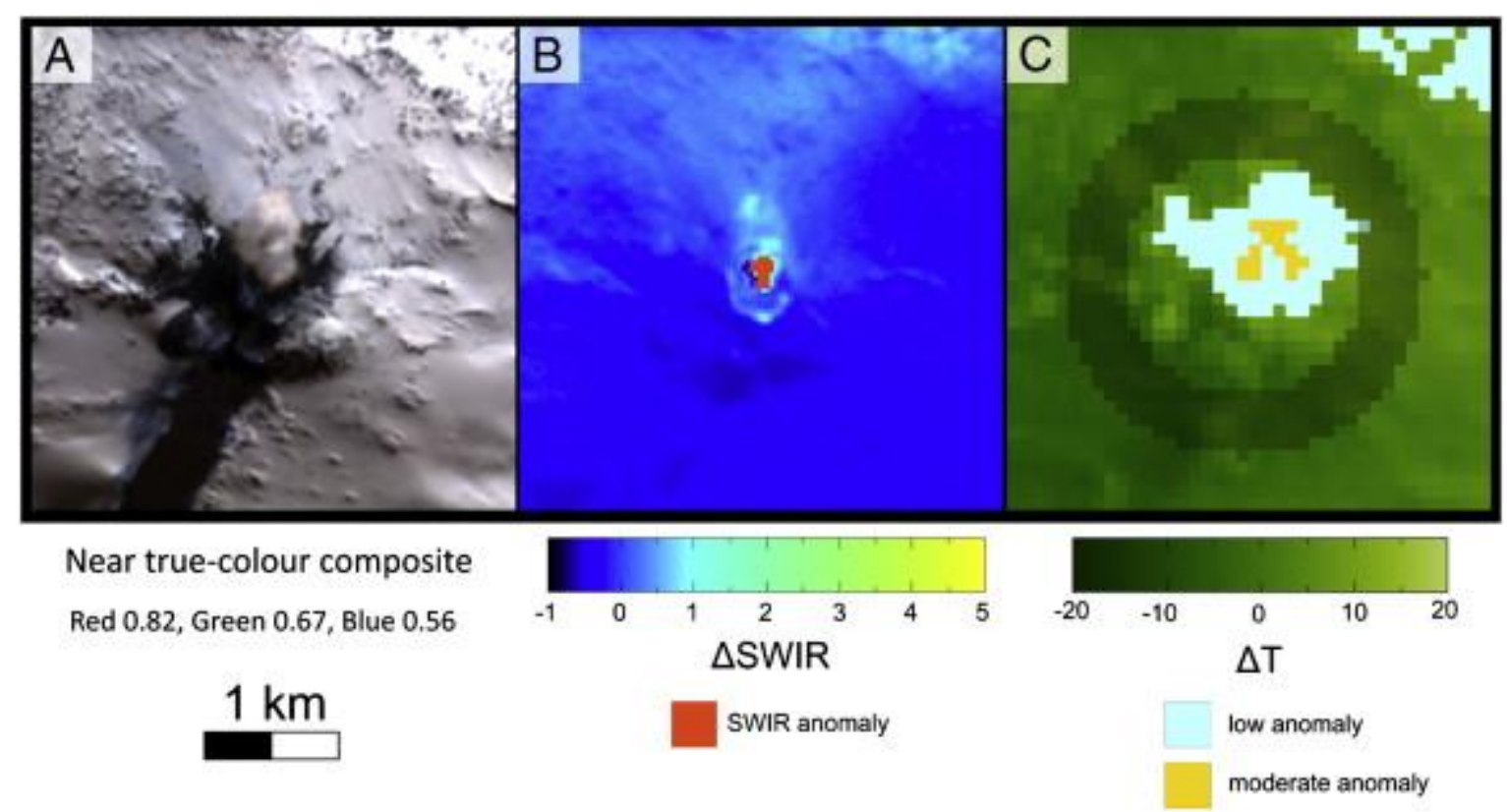

Fig. 13. A vaporous plume, emanating from Erebus on the 27th January 2001 at 20:25 [UTC], is visible in A) VNIR, while associated thermal anomalies are present in B) SWIR and C) temperature images. The background area is highlighted in $\mathrm{c}$ as a dark ring. All images are to the same scale and North is up.

While the low temperature anomaly class is stable at night, the size of moderate and high temperature anomalies (Fig. 12A ii and iii) is stable regardless of the solar elevation angle. A notably large moderate temperature anomaly occurs on 27th January 2001. The image acquired at this time includes the full suite of ASTER sensor bands (Fig. 13) in which a) a thick plume, $\sim 500 \mathrm{~m}$ in diameter, is visible in the VNIR, b) a second thermal feature, probably Werner's fumarole, is discernable in the SWIR bands, and c) a fairly large (i.e. 16 pixel) moderate temperature anomaly and a wide-spread, low temperature anomaly are present; the former appears to be associated with the plume and the later to exposed rock surfaces.

The SWIR anomalies, as a whole, support evidence for a consistent high temperature source. The size of these anomalies typically vary around 10-20 SWIR pixels, i.e. $9000-18,000 \mathrm{~m}^{2}$ (Fig. 12A iv). This is larger than the known area of the lava lake by a factor of $\sim 10$ and likely results from the disparity between the lava lake signal and the immediate crater surroundings. To illustrate this point, imagine an isothermal lava crust at $500{ }^{\circ} \mathrm{C}$ and a surrounding area at $0{ }^{\circ} \mathrm{C}$. If both radiate as blackbodies then the crust will emit $3.4 \times 10^{2} \mathrm{~W} \mathrm{~m}^{-2} \mathrm{sr}^{-1} \mu \mathrm{m}^{-1}$ of spectral radiance at $2 \mu \mathrm{m}$ while the ground would emit only $1.4 \times 10^{-5} \mathrm{~W} \mathrm{~m}^{-2} \mathrm{sr}^{-1} \mu \mathrm{m}^{-1}$ at this wavelength, i.e. a difference of seven orders of magnitude. Scattering (enhanced by the gas and aerosol plume) of just a small fraction (e.g. 1\%) of the lava lake radiation into the 
instantaneous field of view (IFOV) of adjacent detector elements would increase the size of the anomaly such that it does not accurately map to the feature's true dimensions. Another factor that blurs SWIR anomalies is the relationship between the IFOV and detector resampling frequency. Pixels do not map perfectly to areas on the ground from which the radiation was sensed but rather correspond to upwelling radiation received from a wider solid angle defined by the detector's point spread function. Furthermore it is also possible that some hysteresis effects occur as the sensor scans over very hot targets. These factors combine to significantly smear out of the signal of high temperature features such as lava lakes. They may also contribute to increasing the variability in the size of SWIR anomalies through time. Other factors that may increase this variability include those mentioned previously as influences on maximum pixel temperatures (Section 5.1) as well as intermittent activity at Werner's fumarole (which is occasionally incandescent and which was also the site of an ephemeral lava lake in December 2004).

\subsubsection{Láscar}

There is an increase in the size of low, moderate and high temperature anomalies during the first eruptive episode of the Láscar time series (i.e. 20th June 2000 to 18th January 2001), as was also observed in the intensity of the maximum temperature series. A SWIR anomaly is only detected toward the end of this period and at 35 pixels in size, it is one of the largest in this data set. As mentioned previously no dome was observed in the active crater at this time (Bulletin of the Global Volcanism Network. Láscar., 2003) which may suggest that this large SWIR anomaly is due to high temperature fumaroles. There may be a suggestion of a precursory increase in low and moderate temperature anomalies before this eruptive period. Again it is difficult to confirm such a hypothesis given the limited time span between the start of ASTERs operational life and the onset of eruption.

Low, high and, to a lesser extent, moderate anomalies show a progressive increase before the third eruptive period (9th October 2002). This is analogous to the behavior of maximum pixel temperatures and indicates that the size and maximum temperature of thermal anomalies were again correlated at this time. The thermal distribution of anomalies suggests that fumarolic intensity was increasing over this time period, i.e. extensive, low temperature anomaly with an irregular, dynamic shape and a central warmer region that increases in both size and intensity (Fig. 14). SWIR anomalies were relatively extensive and stable in size (Fig. 12B iv) which is consistent with an increase in the flux and/or temperature of emissions from existing fumaroles, as opposed to any significant expansion of the fumarole field. 


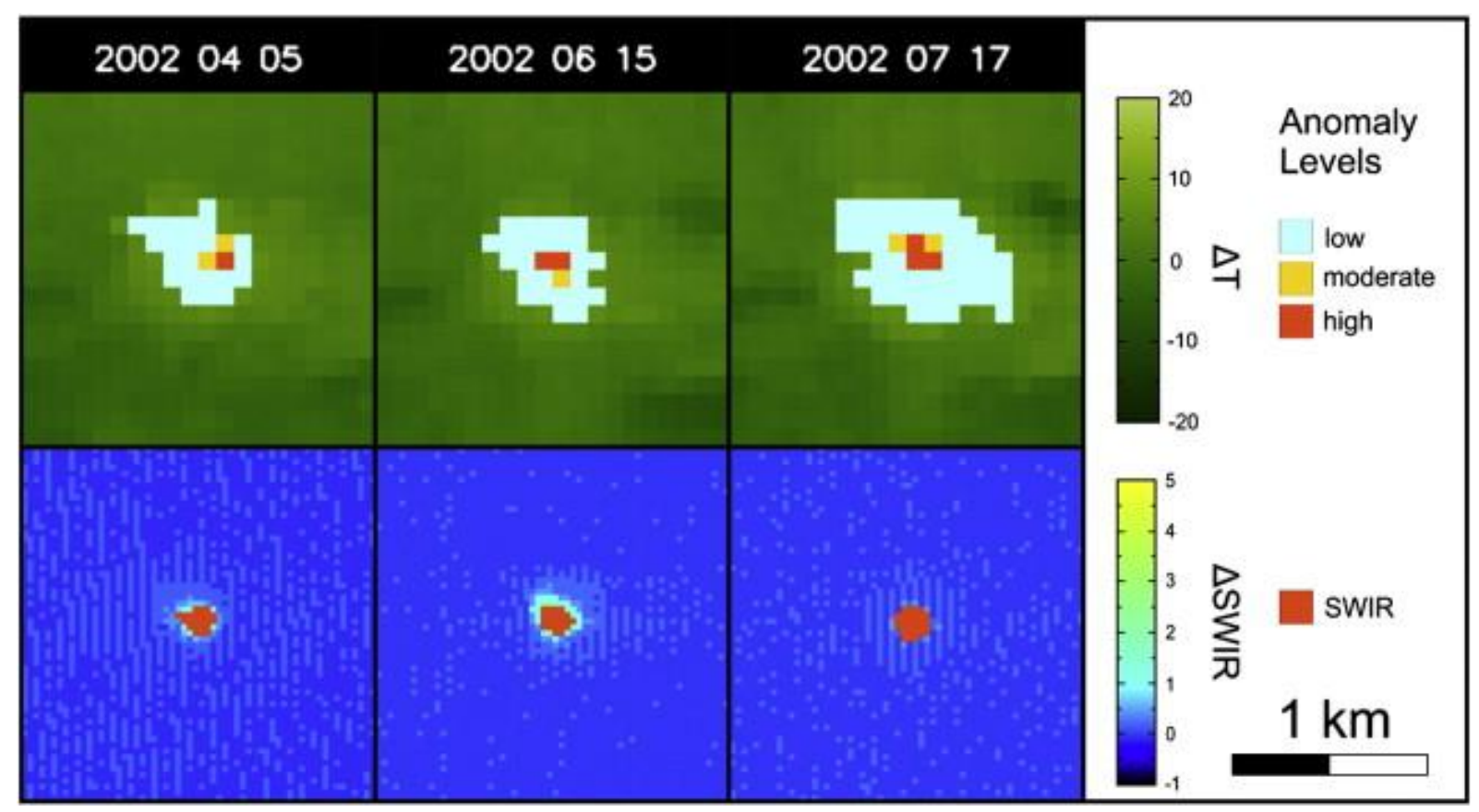

Fig. 14. Increase in the size of low and high temperature anomalies and a consistently large SWIR anomaly precede an eruption of Láscar on 9th October 2002 eruption. All images are to the same scale and North is up.

Low and moderate temperature anomalies display a subtle gradual decrease followed by a sudden increase shortly before the eruption on 11th December 2003. This is perhaps analogous to the behavior of maximum temperatures before the 2006 eruption (Fig. 10B) as well as pre-1993 cycles (Matthews et al., 1997) which have been described above, and may therefore represent a subtle thermal precursor. No high temperature anomalies are recorded at the time and a lack of nighttime scenes precludes the search for a similar pattern in the SWIR time series.

Four separate scenes contain high temperature anomalies within the 6 month period following the December 2003 eruption. This may reflect a post-eruptive increase in fumarolic activity, as was also inferred from the maximum temperature series. Low temperature anomalies show a general decrease in size from around October 2004 until the 4th May 2005 eruption ensues. This contraction may pertain to minor permeability decreases in the upper conduit and could be another example of a subtle thermal precursor. There was no apparent change in the size of moderate, high or SWIR anomalies before this eruption. Again this supports the hypothesis that the source of the eruption was fairly shallow and that the relationship between fluid overpressure and the mechanical strength of containing rock in the upper conduit was already somewhat critical (Fig. 15). 


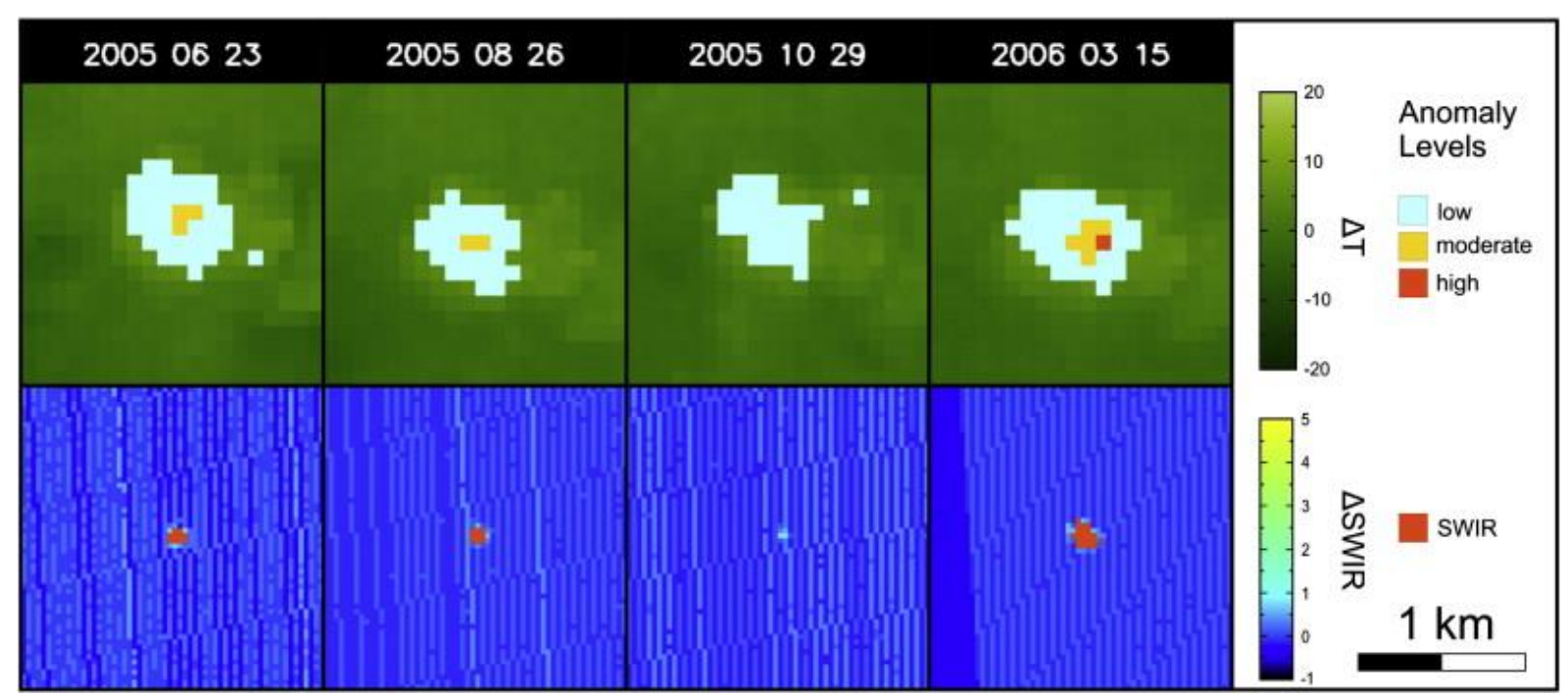

Fig. 15. A gradual decrease followed by an increase in the size and intensity of thermal anomalies precedes a surprisingly intense and long lasting eruptive period at Láscar. All images are to the same scale and North is up.

The low temperature anomaly series shows a distinct increase immediately after the penultimate eruptive episode (i.e. 4th May 2005) and remains elevated up until the beginning of the last eruptive period on 3rd April 2006. Conversely the moderate and SWIR anomalies display a similar pattern to that described for the maximum temperature series, i.e. a gradual decrease followed by an increase before eruption. The onset of this increase occurs somewhere between 2 and 4 months before the start of the subsequent eruptive episode and is even accompanied by some high temperature anomalies. We suggest that degassing was an important component of these anomalies given the extension and spatial configuration of the contemporaneous low temperature anomalies and since no lava dome was observed during field investigations carried out at the time (Bulletin of the Global Volcanism Network. Láscar., 2006).

The final eruptive period (April 2006-July 2007) is characterized by consistent high temperature and SWIR anomalies that are confined to the center of the active crater. It is possible that lava was emplaced at this time although, as mentioned previously, field investigation did not reveal the presence of a dome. Alternatively a high temperature fumarole field may have developed on the crater floor. This is consistent with contemporaneous chemical and isotopic analyses of gas emissions from Láscar, which show that fumaroles within the active crater have a stronger magmatic signature (i.e. high $\mathrm{SO}_{2}, \mathrm{HCL}$ and HF) than fumaroles that are situated on the crater rim (Tassi et al., 2009). Efficient degassing of the upper conduit appears to have been sustained throughout the eruptive period. An abrupt end to moderate, high and SWIR anomalies coincide with the end of the final eruptive period. We note that low temperature anomalies remain quite large in size for approximately 6 months after this eruptive period, suggestive of dispersed fumarolic activity. The remainder of the data set displays considerable variability in the size of low temperature anomalies. This may suggest that Láscar had entered a low level, intermittent degassing regime. 


\section{Discussion}

The maximum temperature above background and the size of anomalous areas are both measures that can provide insight into dynamic volcanic behavior and therefore be useful in a monitoring context. The maximum pixel temperature however can be less meaningful for subpixel-sized lava bodies. Several factors that may cause the resultant scattered response have been discussed above. Here we briefly explore the dependence of the maximum pixel temperatures on the maximum fraction of the lava lake in a given pixel. We then go on to comment on the size and intensity of thermal anomalies and their potential monitoring value at other volcanoes.

\subsection{Scatter in maximum $\Delta \mathrm{T}$ at Erebus}

The spectral radiance, $\mathrm{L}_{(\lambda, \mathrm{T})}$, emitted by a surface is described by the Planck function:

$$
L_{(\lambda, T)}=\varepsilon_{\lambda} c_{1} \lambda^{-5} /\left[\exp \left(\frac{c_{2}}{\lambda T}\right)-1\right]
$$

at wavelength, $\lambda$, and thermodynamic temperature, $T$, and where $\varepsilon_{\lambda}$ is spectral emissivity, and $c_{1}$ and $c_{2}$ are the radiation constants (i.e. $c_{1}=2 \pi h c=3.742 \times 10^{-16} \mathrm{~W} \mathrm{~m}^{2}$ and $c_{2}=h c / k=1.439 \times 10^{-2} \mathrm{mK}$; where $h$ is the Planck constant, $c$ the speed of light and $k$ the Boltzmann constant). Assuming the spectral radiance and emissivity are known, the temperature of a remote surface can be estimated by rearranging thus:

$$
T_{(\lambda, L)}-c_{2} / \lambda \ln \left(\frac{\varepsilon \lambda C_{1} \lambda^{-5}}{L}+1\right) .
$$

As the emissivity of our target area was not known we assumed a maximum of 0.97 and then applied the Normalized Emissivity Method (Realmuto, 1990) for temperature retrieval with Eq. 7. In practice, the resultant pixel-integrated temperature is weighted according to the bandpass function of the sensor and the Planck radiation distribution of the target. As the radiation emitted from a surface is non-linearly dependent on temperature (i.e. Eq. $\underline{6}$ ) any temperature retrieval will tend to diverge from the average temperature of subpixel thermal components unless the target surface is isothermal. The magnitude of this divergence is usually small for typical terrestrial surfaces as targets tend to have limited sub-pixel thermal contrast and low temperatures (i.e. $<100{ }^{\circ} \mathrm{C}$; Garratt, 1992). However, it can be large in the presence of a high temperature feature with strong spatial variability (such as a fissured active lava surface).

To illustrate the effect that Erebus lava lake might have on a maximum pixel temperature we model the active crater as a three component, blackbody system made up of a crust of lava at $500{ }^{\circ} \mathrm{C}$ which can have incandescent cracks at $900{ }^{\circ} \mathrm{C}$ (Calkins et al., 2008) and is surrounded by ground at $-30{ }^{\circ} \mathrm{C}$. The lake can range in size from 700 to $1400 \mathrm{~m}^{2}$, the maximum fractional area of the lake within any given ASTER TIR pixel can therefore range between 2.2 and $17.3 \%$. The lower fractional limit is calculated by assuming that the smallest possible lake area can be equally divided between four pixels. The upper limit represents the situation in which the largest lake area is completely imaged within a single pixel. The maximum proportion of incandescent cracks within the lake is set as 0.1 . This is because the maximum reported area of bubble burst (i.e. $60 \mathrm{~m}^{2}$; Calkins et al., 2008) would occupy $8.6 \%$ of the smallest modeled lake size. 
The average temperature of a 3 component thermal system is given by Eq.(8), where $\mathrm{f}$ is the fractional area of a component at temperature $\mathrm{T}$, and the subscripts $\mathrm{h}, \mathrm{c}$ and $\mathrm{b}$ denote hot incandescent cracks, lava crust and non-active background, respectively.

\section{Taverage $=f h T h+f c T c+f b T b$}

The measured pixel temperature (Eq. 7), on the other hand, depends on the sum of the individual radiance components (Eq. 9), which is not linearly related to temperature and will therefore result in divergence between the measured and average temperature.

$L$ total $=f h L(\lambda, T h)+f c L(\lambda T c)+f b L(\lambda, T b)$

where $\mathrm{L}_{\text {total }}$ is the total spectral radiance measured by a single detector element whose waveband has a mid-point at $\lambda$, and $\mathrm{L}$ is the blackbody radiance emitted by isothermal components at temperatures $T_{h}, T_{c}$ and $T_{b}$. The maximum pixel temperature within a given scene will therefore not only depend on the physical properties of the target area but also on the maximum fractional area of the lava lake within an IFOV of a given detector element of a sensor array.

Absorption of volcanic gas species (e.g. $\mathrm{H}_{2} \mathrm{O}$ and $\mathrm{SO}_{2}$ ) is not modeled here as it will have limited affect on temperatures calculated using the Normalized Emissivity Method. This is because the NEM algorithm automatically selects the band which has the largest brightness temperature and is therefore likely to avoid bands that have undergone significant amounts of wavelength dependent absorption. Field measurements have shown however that transmission across the TIR waveband (i.e. $7-13 \mu \mathrm{m}$ ) is strongly attenuated by volcanic aerosols (Sawyer and Burton, 2006). This will affect temperature estimates as even the largest brightness temperatures will have been significantly reduced.

We therefore model the dependence of pixel temperatures on the presence of aerosols as well, considering the case in which either a) no aerosols are present or b) aerosols cause a 30\% reduction in transmittance across all wavelengths (Fig. 16). 

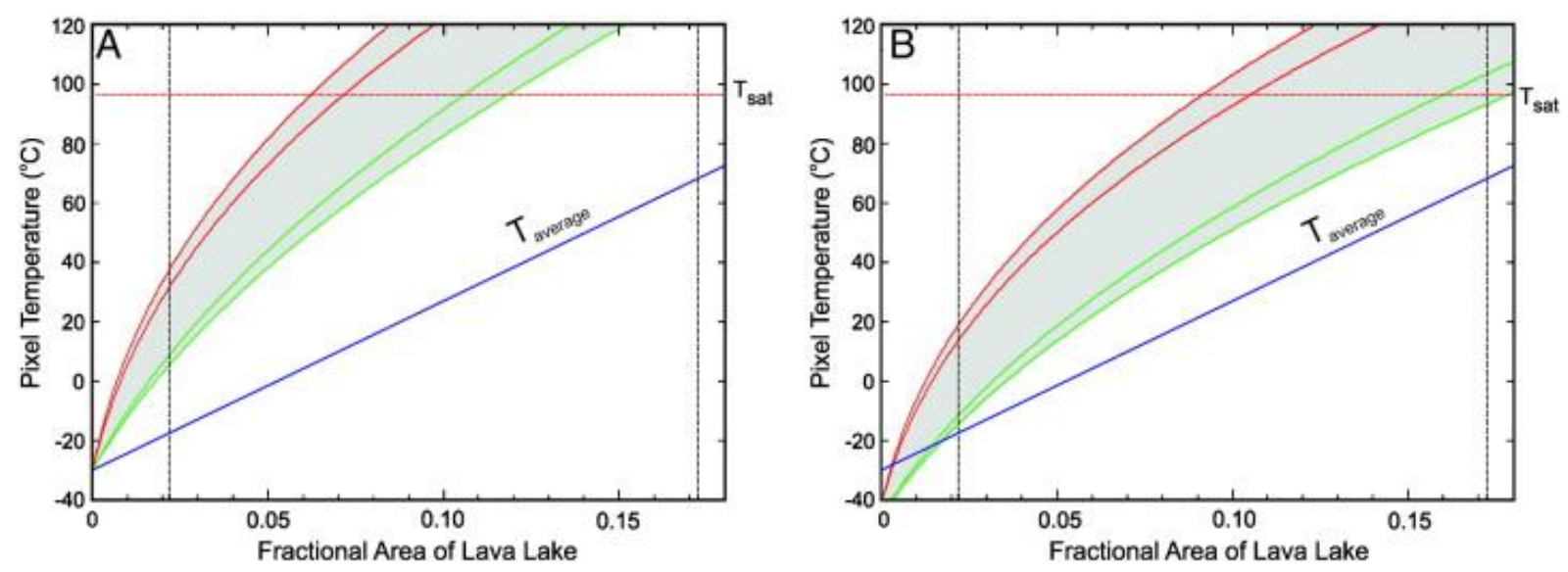

Fig. 16. Pixel temperature solutions (gray areas) for ASTER TIR bands as a function of the fractional area of a lava lake within a given pixel. The average temperature of sub-pixel components is given (solid blue lines). Aerosols can be either a) not present or b) cause a 30\% reduction in transmittance. The maximum fractional area of the lake can range from 0.022 to 0.173 (vertical dashed lines). Temperature ranges from ASTER bands 10 and 14 are plotted as pairs of red and green lines respectively and denote response ranges for the cases in which incandescent material occupies zero or 0.1 of the lake. The saturation temperature of an ASTER TIR pixel, $\mathrm{T}_{\text {sat }}$, is given as a horizontal red dotted line.

The pixel temperature solutions (gray areas) are sensitive to the fractional area of the lava lake and can exceed the actual temperature (blue lines) by several tens of degrees. Significant scatter in maximum temperatures could therefore be produced by small (i.e. sub-pixel sized) variations in: lake size, spatial alignment between the target and pixel IFOVs, and the proportion of incandescent cracks within the lake. Aerosols can significantly reduce temperature solutions (Fig. 16B) and will act to provide further variability in maximum pixel temperatures.

\subsection{Background temperatures at other volcanoes}

The global distribution of volcanoes and their varying topographies and compositions can lead to markedly different background temperatures from one edifice to the next. A standardized method for measuring background temperatures would facilitate comparisons between volcanoes situated around the world. We attempt to make steps toward such a standardized approach by defining a background area that is situated as close to the region of activity as possible without becoming volcanically heated and while also meeting a minimum size constraint. For Erebus and Láscar volcanoes a ring-shaped background area was found to be suitable because activity is restricted to a single crater. However, different styles of volcanism (e.g. those with fissural morphologies, such as Erta 'Ale and Eyjafjallajökull) may require different background geometries (e.g. an ellipse).

To isolate a volcanic thermal signal it is necessary to estimate the background value. Furthermore, automatic anomaly detection requires that the natural variability in the background value is quantified. These can both be achieved in a straightforward, unbiased manner through the use of arithmetic averages and standard deviation. However, such background statistics could be compromised in the case that hot volcanic material (e.g. lava 
and/or pyroclastic flows) fall in the background area. For global monitoring applications it would therefore be necessary to screen automatically for anomalous pixels in the background area. This could be achieved through the use of in-scene statistics or expected background values as derived from time series analysis. It will probably be necessary to remove only the more extreme anomalies from the background area as subtle anomalies are unlikely to affect background statistics significantly. This is because hot volcanic products, such as lava and pyroclastic flows, tend to be channelized and narrow in size close to their source region. As such they will occupy very small proportions of a background area that encircles the entire source region.

\subsection{Monitoring implications}

Two clear thermal precursors and two subtle thermal precursors were identified in the Láscar time series. The well-defined precursors are i) an increase in the size of low, moderate and high temperature anomalies as well as consistently large SWIR anomalies for the 6-9 months preceding the 9th October 2002 eruptive episode, and ii) a gradual decrease, followed by an increase, in the size of moderate temperature anomalies which is accompanied by high temperature anomalies for roughly 3 months preceding the final eruptive period (i.e. start date 3rd April 2006). The subtle thermal anomalies consisted of i) a gradual decrease followed by a sudden increase in the size of low and moderate temperature anomalies before the 11th December 2003 eruptive episode, and ii) a gradual decrease in low temperature anomalies over an 6 month period preceding the 4th May 2005 eruption. Monitoring efforts at Láscar could thus be usefully augmented by systematic spaceborne remote sensing in the future, especially given that the thermal precursors span timescales of a few months and therefore could have predictive value.

We envisage that measuring the size and intensity of thermal anomalies will provide useful constraints for volcano monitoring teams in general. For example, the detection of a large, hot body would suggest significant activity has recently occurred and may indicate the presence of a lava flow or fresh pyroclastic material. The distinction between plumes and lava flows may also be facilitated by the joint measurement of spatial and thermal information. Plumes will tend to be relatively low in temperature, extensive, irregular shaped, dynamic regions while lava flows will tend to display higher temperatures and more consistent boundaries through time which have either point (i.e. dome) or lobate (i.e. flow) geometries. Such distinction, however, will often be inconclusive for sub-pixel sized bodies as no spatial information is available and strong thermal heterogeneities can lead to unreliable pixel temperatures at this spectral resolution. Significant post-eruptive changes in the size and or intensity of thermal anomalies can help to identify the end of an eruptive episode. This is important because the duration of an eruptive episode has been shown to be statistically related to both the repose time as well as the size of the next eruption (Marzocchi and Zaccarelli, 2006).

\section{Conclusion}

The spatial extent of anomalously hot pixels was introduced as a monitoring parameter for active volcanoes. Comparisons were made to short-wave infrared anomalies as well as to a previously reported thermal metric (i.e. the maximum temperature above background). We show that the size of anomalous regions better correlates to eruptive activity than maximum temperature alone. Measuring the size and intensity of thermal features can be used to improve our understanding of volcanic systems by direct observation, as in this study, or 
through incorporation into probabilistic or physical models. Future algorithms for volcanic activity detection may include a search for thermal anomalies which exceed a certain size and/or intensity. We note that such observations are only possible because of ASTER's combined spatial and spectral resolution. Even so, future studies would benefit from a new generation of orbital, infrared sensors with improved spatial resolution, such as NASA's proposed HyspIRI mission (Chien et al., 2009). Pixel saturation issues could also be mitigated by extending the dynamic range of detector elements.

\section{Acknowledgments}

This work was carried out at the University of Campinas, Brazil and was funded by a CAPES (Coordenação de Aperfeiçoamento de Pessoal de Nível Superior) doctoral research grant. CO thanks the NERC National Centre for Earth Observation for generous support (Dynamic Earth Theme 6). Comments from two anonymous reviewers were also well received.

\section{References}

Bulletin of the Global Volcanism Network. Soufrière Hills., 1995 Bulletin of the Global Volcanism Network. Soufrière Hills. 1995. 20 (6).

Bulletin of the Global Volcanism Network. Láscar., 2000 Bulletin of the Global Volcanism Network. Láscar. 2000. 25 (6).

Bulletin of the Global Volcanism Network. Láscar., 2003 Bulletin of the Global Volcanism Network. Láscar. 2003. 28 (3).

Bulletin of the Global Volcanism Network. Láscar., 2004 Bulletin of the Global Volcanism Network. Láscar. 2004. 29 (1).

Bulletin of the Global Volcanism Network. Láscar., 2005 Bulletin of the Global Volcanism Network. Láscar. 2005. 30 (5).

Bulletin of the Global Volcanism Network. Láscar., 2006 Bulletin of the Global Volcanism Network. Láscar. 2006. 31 (4).

Bulletin of the Global Volcanism Network. Láscar., 2007 Bulletin of the Global Volcanism Network. Láscar. 2007. 32 (9).

Calkins et al., 2008 J. Calkins, C. Oppenheimer, P.R. Kyle Ground-based thermal imaging of lava lakes at Erebus volcano, Antarctica Journal of Volcanology and Geothermal Research, 177 (3) (2008), pp. 695-704

Carter et al., 2008 A.J. Carter, O. Girina, M.S. Ramsey, Y.V. Demyanchu ASTER and field observations of the 24 December 2006 eruption of Bezymianny Volcano, Russia Remote Sensing of Environment, 112 (2008), pp. 2569-2577

Chien et al., 2009 S. Chien, D. Silverman, A.G. Davies, D. Mandl Onboard science processing concepts for the HyspIRI Mission IEEE Intelligent Systems, 24 (6) (2009), pp. $12-19$ 
Csatho et al., 2008 B. Csatho, T. Schenk, P. Kyle, T. Wilson, W.B. Krabill Airborne laser swath mapping of the summit of Erebus volcano, Antarctica: Applications to geological mapping of a volcano Journal of Volcanology and Geothermal Research, 177 (2008), pp. 531-548

Davies et al., 2008 A.G. Davies, J. Calkins, L. Scharenbroich, R.G. Vaughan, R. Wright, P. Kyle, R. Castano, S. Chien, D. Tran Multi-instrument remote and in situ observations of the Erebus Volcano (Antarctica) lava lake in 2005: a comparison with the Pele lava lake on the Jovian moon lo Journal of Volcanology and Geothermal Research, 177 (3) (2008), pp. $705-724$

de Silva and Francis, 1991 de Silva, S.L. and Francis, P., 1991. Volcanoes of the Central Andes.

Esser et al., 2004 R.P. Esser, P.R. Kyle, W.C. McIntosh Ar-40/Ar-39 dating of the eruptive history of Mount Erebus, Antarctica: volcano evolution Bulletin of Volcanology, 66 (8) (2004), pp. 671-686

Francis and Rothery, 1987 Francis, P. and Rothery, D., 1987. Using the Landsat Thematic Mapper to detect and monitor active volcanoes: An example from northern Chile. Geology: 614-617.

Garratt, 1992 J.R. Garratt Extreme maximum land surface temperatures Journal of Applied Meteorology, 31 (9) (1992), pp. 1096-1105

Gardeweg et al., 1994 M.C. Gardeweg, G. Fuentealba, M. Murillo, M.E. Petit-Breuth Volcan Láscar Geologia y evaluacion del riesgo volcanoico: Altiplano II Region, Servicio Nacional de Geologia y Mineria, Chile (1994)

Giggenbach et al., 1973 Giggenbach, W., Kyle, P. and Lyon, G., 1973. Present volcanic activity on Mt. Erebus, Ross Island, Antarctica. Geology: 135-156.

Harpel et al., 2004 C.J. Harpel, P.R. Kyle, R.P. Esser, W.C. McIntosh, D.A. Caldwell Ar40/Ar-39 dating of the eruptive history of Mount Erebus, Antarctica: summit flows, tephra, and caldera collapse Bulletin of Volcanology, 66 (8) (2004), pp. 687-702

Harris et al., 1999 A.J.L. Harris, R. Wright, L.P. Flynn Remote monitoring of Mount Erebus volcano, Antarctica, using polar orbiters: progress and prospects International Journal of Remote Sensing, 20 (15-16) (1999), pp. 3051-3071

Hirn et al., 2008 B. Hirn, C. Di Bartola, F. Ferrucci Spaceborne monitoring 2000-2005 of the Pu'u 'O'o-Kupaianaha (Hawaii) eruption by synergetic merge of multispectral payloads ASTER and MODIS leee Transactions on Geoscience and Remote Sensing, 46 (10) (2008), pp. 2848-2856

Kelly et al., 2008 P.J. Kelly, P.R. Kyle, N.W. Dunbar, K.W.W. Sims Geochemistry and mineralogy of the phonolite lava lake, Erebus volcano, Antarctica: 1972-2004 and comparison with older lavas Journal of Volcanology and Geothermal Research, 177 (3) (2008), pp. 589-605 
Kyle et al., 1992 P. Kyle, J.A. Moore, M.F. Thirlwall Petrologic evolution of anorthoclase phonolite lavas at Mount Erebus, Ross Island, Antarctica Journal of Petrology, 33 (1992), pp. $849-875$

Marzocchi and Zaccarelli, 2006 Marzocchi, W. and Zaccarelli, L., 2006. A quantitative model for the time-size distribution of eruptions. Journal of Geophysical Research-Solid Earth, 111(B4).

Matthews et al., 1994 Matthews, S.J., Jones, A.P. and Gardeweg, M.C., 1994. Láscar Volcano, Northern Chile: evidence for steady-state disequilibrium. Journal of Petrology: 401-432.

Matthews et al., 1997 S.J. Matthews, M.C. Gardeweg, R.S.J. Sparks The 1984 to 1996 cyclic activity of Láscar Volcano, northern Chile: cycles of dome growth, dome subsidence, degassing and explosive eruptions Bulletin of Volcanology, 59 (1) (1997)

Oppenheimer et al., 1993 Oppenheimer, C., Francis, P., Rothery, D., Carlton, R. and Glaze, L., 1993. Infrared Image Analysis of Volcanic Thermal Features: Láscar Volcano, Chile, 1984-1992. Journal of Geophysical Research: 4269-4286.

Oppenheimer et al., 2009 C. Oppenheimer, A. Lomakina, P.R. Kyle, N.G. Kingsbury, M. Boichu Pulsatory magma supply to a phonolite lava lake Earth and Planetary Science Letters, 284 (2009), pp. 392-398

Oppenheimer et al., 2011 Oppenheimer, C., Moretti, R., Kyle, P., Eschenbacher, A., Lowenstern, J. \& Hervig, R., 2011. Mantle to surface degassing of alkalic magmas at Erebus volcano, Antarctica. Earth and Planetary Science Letters, in review.

Pavez et al., 2006 A. Pavez, D. Remy, S. Bonvalat, M. Diament, G. Gabalda, J.L. Froger, P. Julien, D. Legrand, D. Moisset Insight into ground deformations at Lascar volcano (Chile) from SAR interferometry, photogrammetry and GPS data: implications on volcano dynamics and future space monitoring Remote Sensing of Environment, 100 (3) (2006), pp. 307-320

Pieri and Abrams, 2005 D. Pieri, M. Abrams ASTER observations of thermal anomalies preceding the April 2003 eruption of Chikurachki volcano, Kurile Islands, Russia Remote Sensing of Environment, 99 (2005), pp. 84-94

Ramsey and Dehn, 2004 M. Ramsey, J. Dehn Spaceborne observations of the 2000 Bezymianny, Kamchatka eruption: the integration of high-resolution ASTER data into near real-time monitoring using AVHRR Journal of Volcanology and Geothermal Research, 135 (2004), pp. 127-146

Realmuto, 1990 V.J. Realmuto Separating the Effects of Temperature and Emissivity: Emissivity Spectrum Normalization, 2nd TIMS WorkshopJPL Publication, Pasadena, CA: Jet Propul. Lab (1990) pp. 90-55

Ross, 1847 J.C. Ross A Voyage of Discovery and Research in the Southern and Antarctic Regions John Murray, London (1847) 
Sawyer and Burton, 2006 G.M. Sawyer, M.R. Burton Effects of a volcanic plume on thermal imaging data Geophysical Research Letters, 33 (14) (2006)

Scientific Event Alert Network. Nevado del Ruiz., 1985 Scientific Event Alert Network. Nevado del Ruiz. 1985.05 and 07 (10).

Smithsonian Institution, n.d Smithsonian Institution Láscar Eruptive History Available at: http://www.volcano.si.edu/world/volcano.cfm?vnum=1505-10=\&volpage=erupt

Smithsonian Institution. Bezymianny Weekly Reports. May, 2010 Smithsonian Institution. Bezymianny Weekly Reports. May 2010. Available at:

http://www.volcano.si.edu/world/volcano.cfm\%vnum=1000-

$25=\&$ volpage=weekly\#May2010

Tassi et al., 2009 F. Tassi, F. Aguilera, O. Vaselli, E. Medina, D. Tedesco, A. Delgado Huertas, R. Poreda, S. Kojima The magmatic- and hydrothermal-dominated fumarolic system at the active crater of Lascar volcano, northern Chile Bulletin of Volcanology, 71 (2) (2009), pp. 171-183

Vaughan and Hook, 2006 R.G. Vaughan, S.J. Hook Using satellite data to characterize the temporal thermal behavior of an active volcano: Mount St. Helens, WA Geophysical Research Letters, 33 (2006), p. L20303

Vaughan et al., 2008 R.G. Vaughan, M. Kervyn, V. Realmuto, M. Abrams, S.J. Hook Satellite measurements of recent volcanic activity at Oldoinyo Lengai, Tanzania Journal of Volcanology and Geothermal Research, 173 (2008), pp. 196-206

Vaughan et al., 2010 R.G. Vaughan, L.P. Keszthelyi, A.G. Davies, D.J. Schneider, C. Jaworowski, H. Heasler Exploring the limits of identifying sub-pixel thermal features using ASTER TIR data Journal of Volcanology and Geothermal Research, 189 (3-4) (2010), pp. 225-237

Wooster, 2001 Wooster, M.J., 2001. Long-term infrared surveillance of Láscar Volcano: contrasting activity cycles and cooling pyroclastics. Geophysical Research Letters: 847850 .

Wright and Pilger, 2008 R. Wright, E. Pilger Satellite observations reveal little interannual variability in the radiant flux from the Mount Erebus lava lake Journal of Volcanology and Geothermal Research, 177 (3) (2008), pp. 687-694

Yamaguchi et al., 1998 Y. Yamaguchi, A.B. Kahle, H. Tsu, T. Kawakami, M. Pniel Overview of Advanced Spaceborne Thermal Emission and Reflection Radiometer (ASTER) IEEE Transactions on Geoscience and Remote Sensing, 36 (1998), pp. 1062-1071 